\title{
Effect of Chitosan on the Performance of NiMoP-Supported Catalysts for the Hydrodesulfurization of Dibenzothiophene
}

\author{
Guillermina Ríos-Caloch, ${ }^{1}$ Víctor Santes, ${ }^{1}$ José Escobar, ${ }^{2}$ Patricia Pérez-Romo, \\ Leonardo Díaz, ${ }^{2}$ and Luis Lartundo-Rojas ${ }^{3}$ \\ ${ }^{1}$ Departamento de Biociencias e Ingeniería, CIIEMAD-IPN, 07340 México, DF, Mexico \\ ${ }^{2}$ Gerencia de Refinación de Hidrocarburos, Instituto Mexicano del Petróleo, 07730 México, DF, Mexico \\ ${ }^{3}$ Centro de Nanociencias y Micro y Nanotecnologías, Instituto Politécnico Nacional, UPALM, Zacatenco, 07738 México, DF, Mexico \\ Correspondence should be addressed to Víctor Santes; vsantes@ipn.mx
}

Received 2 October 2015; Revised 15 January 2016; Accepted 19 January 2016

Academic Editor: Ilaria Armentano

Copyright (C) 2016 Guillermina Ríos-Caloch et al. This is an open access article distributed under the Creative Commons Attribution License, which permits unrestricted use, distribution, and reproduction in any medium, provided the original work is properly cited.

\begin{abstract}
Chitosan-added NiMoP catalysts supported on alumina and alumina-titania were studied in the hydrodesulfurization (HDS) of dibenzothiophene (DBT). The preparation of catalysts containing Mo (12 wt\%), Ni (3 wt\%), P (1.6 wt\%), and chitosan/nickel = 2 (mol ratio) was accomplished by sequential pore-filling impregnation varying the order of chitosan integration. Materials were characterized by DRIFTS, TPR, TG-DTA, and XPS techniques. The TG-DTA study showed that the nature of the support influences the degradation of chitosan onto the catalytic materials and also influences the HDS of DBT and the product distribution as well. The series of catalysts supported on alumina presented the most remarkable effect of chitosan, in which the $\mathrm{OH}$ and $\mathrm{NH}$ groups of the organic molecule interact with acid sites of the support weakening the interaction between alumina and deposited metal phases. In all cases, DBT was converted mainly through direct sulfur removal. The catalysts ChP3/A (alumina support impregnated with chitosan in phosphoric acid solution, prior to NiMoP deposition) and ChP4/AT (alumina-titania support impregnated with NiMoP solution, prior to contacting with a solution comprising chitosan and phosphorus) exhibited the best performance in HDS reactions and also showed the highest selectivity in biphenyl formation. Presence of carbonaceous residua on the catalyst's surface, as shown by XPS, could enhance the HDS activity over the ChP4/AT sample.
\end{abstract}

\section{Introduction}

Stricter sulfur specifications for diesel fuel worldwide present a great challenge to refiners. In Mexico, when proposed official legislation restricting diesel to $<15 \mathrm{ppm}$ sulfur content came into effect in 2006 for the main cities, PEMEX Refining (state-owned refining company) began to modify its facilities to fulfill the new regulations across the entire country. It is well accepted that the use of chelating agents in the preparation of $\mathrm{Co}(\mathrm{Ni})-\mathrm{Mo}(\mathrm{W})$ leads to more active hydrodesulfurization catalysts due to the fact that chelating agents delay sulfidation of the $\mathrm{Ni}$ or Co promoter, which in turn accounts for the formation of $\mathrm{Ni}$ or Co sulfides after the Mo phase sulfidation [1]. Recent studies concerning the influence of complexing agents such as EDTA (ethylenediaminetetraacetic acid) and NTA (nitrilotriacetic acid) on the adsorption of nickel and molybdate ions on alumina support have shown that changes in the metal ions-support surface interactions could be due to addition of chelating agents during impregnation [2].

The strong interaction between metallic phases and support influences the dispersion and sulfidation of the active phases. Alumina has been predominantly used as a support for a long time; however, its highly strong metal-support interaction results in Mo species difficult to sulfide to generate the so-called NiMoS-type structures which are described as the most active species towards hydrodesulfurization [3]. However, in order to improve the catalytic activity toward HDS, the use of supports such as $\mathrm{TiO}_{2}-\mathrm{Al}_{2} \mathrm{O}_{3}$ [4-7] and $\mathrm{SiO}_{2}-\mathrm{Al}_{2} \mathrm{O}_{3}[1,8]$ has been reported. Modification of $\mathrm{Al}_{2} \mathrm{O}_{3}$ by incorporating phosphorus, fluorine, and boron [9-11] 
has also been described. On the other hand, it is also well established that the addition of organic agents containing atoms with lone-pair electrons during the catalyst preparation is an effective approach to improve catalytic activity. In this regard, nitrilotriacetic acid (NTA), ethylenediaminetetraacetic acid (EDTA), and 1,2-cyclohexanediaminetetraacetic acid (CyDTA) have been used as additives to prepare hydrotreating catalysts and have shown positive results $[1,12-$ 14].

The literature shows ever-growing interest concerning the effect of chelating agents on hydrodesulfurization activity.

It is also known that chitosan provides suitable configuration for efficient complexation to metal cations [15]. In this context, it is reported that hydroxyl and amino groups in the chitosan structure could form strong coordinative bonds with $\mathrm{Ni}^{2+}$ cations [15] which could result in delayed sulfidation of nickel species. In view of the strong demand for ULSD (ultralow sulfur diesel) fuels, the development of novel and highly active catalysts for ultra-deep hydrodesulfurization (HDS) to remove the most refractory heterocyclic compounds in oil-derived middle distillates will become of paramount importance.

In this line, we recently reported the effect of chitosan addition on $\mathrm{NiMo} / \mathrm{Al}_{2} \mathrm{O}_{3}$ catalysts for dibenzothiophene hydrodesulfurization [16], in which we varied the content of organic agent in various formulations. From that study we observed that the higher the concentration of chitosan, the lower the activity of the studied alumina-supported NiMo catalysts. We proposed that the increase in the amount of chitosan could lead to higher concentrations of carbonaceous residue on the surface of the catalysts; however, the DDS (direct desulfurization pathway) product yield was enhanced with the concentration of the organic additive in the formulations. These findings were in line with the results found by Valencia and Klimova [17], in which the catalytic activity increased by citric acid addition as compared to catalyst without organic additive; however, larger citric acid amounts decreased the catalytic activity but clearly promoted the direct desulfurization route. Similar results were previously reported by Escobar et al. [18], in which the decrease in HDS activity could be attributed to the deposited carbon from the decomposition of the organic additive leading to a partial plugging of the porous network in those materials where organic agent was added in higher amounts. The differences observed in yield towards various products over various catalysts studied could indicate that the nature of the active sites present had been modified by the organic additive. Bataille et al. [19] suggested that this fact is associated with a more efficient promotion of $\mathrm{MoS}_{2}$ slabs by $\mathrm{Ni}$ in those catalysts; in agreement with these findings, Kaluža et al. [20] reported similar results for Mo catalysts promoted by Co.

In the present work, we prepared two series of NiMoP catalysts supported on alumina and alumina-titania using chitosan as additive in the impregnating aqueous solutions, varying the order of precursors addition. The catalytic activity of these materials was tested in liquid-phase dibenzothiophene hydrodesulfurization.
TABLE 1: Materials supported on alumina and on alumina-titania.

\begin{tabular}{lcc}
\hline Sample & First impregnation & Second impregnation \\
\hline ChP1/A & ChP & - \\
ChP2/A & NiMoP & - \\
ChP3/A & ChP & NiMoP \\
ChP4/A & NiMoP & ChP \\
ChP1/AT & $\mathrm{ChP}$ & - \\
ChP2/AT & NiMoP & - \\
ChP3/AT & $\mathrm{ChP}$ & $\mathrm{NiMoP}$ \\
ChP4/AT & $\mathrm{NiMoP}$ & $\mathrm{ChP}$ \\
\hline
\end{tabular}

\section{Experimental}

2.1. Catalyst Preparation. Two series of NiMoP catalysts supported on alumina (surface area: $307 \mathrm{~m}^{2} / \mathrm{g}$ and pore volume: $0.9 \mathrm{~cm}^{3} / \mathrm{g}$ [21]) and alumina-titania (10 $\mathrm{wt} \%$ of $\mathrm{TiO}_{2}$, surface area: $242 \mathrm{~m}^{2} / \mathrm{g}$ and pore volume: $0.76 \mathrm{~cm}^{3} / \mathrm{g}$ [5]) were prepared by sequential pore-filling impregnation procedure. The order of impregnation of various catalysts prepared is summarized in Table 1 . The reagents used were molybdenum trioxide (Aldrich, 99.5\%), nickel hydroxycarbonate (II) tetrahydrate (Aldrich), and phosphoric acid (J. T. Baker, 85.2\%). Mo, $\mathrm{Ni}$, and $\mathrm{P}$ contents were 12,3 , and $1.6 \mathrm{wt} \%$ in the final catalysts, respectively. Chitosan (Aldrich, $83.3 \%$ deacetylation degree) was added as organic additive. The chitosan/ $\mathrm{Ni}=2$ ratio was kept constant in all materials. In order to obtain the catalysts supported on alumina (A) and alumina-titania (AT), two different solutions were prepared. The first solution containing chitosan $(0.9876 \mathrm{~g}$ of $\mathrm{Ch})$ and phosphoric acid $\left(0.175 \mathrm{~mL}\right.$ of $\left.\mathrm{H}_{3} \mathrm{PO}_{4}\right)$ was named $\mathrm{ChP}$; the second solution containing the proper amounts of the reagents to provide the nickel (Ni), molybdenum (Mo), and (P) contents above stated was named NiMoP.

The catalysts supported on alumina were prepared as follows: Sample ChP1/A consists of alumina support impregnated with chitosan in phosphoric acid solution and ChP2/A resulted from the impregnation of alumina support with NiMoP solution. Sample ChP3/A was prepared with $\mathrm{ChP}$ and NiMoP sequentially impregnated solutions. Sample ChP4/A was obtained in the same way as sample $\mathrm{ChP} 3 / \mathrm{A}$, but varying the order of impregnation (see Table 1). After each impregnation the materials were kept at room temperature for $12 \mathrm{~h}$ and then they were dried at $120^{\circ} \mathrm{C}$ for $6 \mathrm{~h}$. The same procedure was followed to prepare catalysts supported on alumina-titania. Sample ChP2/AT was only impregnated with NiMoP solution without chitosan. Calcination was omitted in all samples to avoid chitosan decomposition. In all cases, $10 \mathrm{~g}$ of support and $10 \mathrm{~mL}$ of the proper solutions were used.

2.2. Catalyst Characterization. Thermal analyses of all samples were determined with a SETSYS 12 simultaneous thermal analyzer (Setaram). The sample weight was kept at $\sim 100 \mathrm{mg}$. The samples were heated from room temperature up to $1000^{\circ} \mathrm{C}$ at a constant heating rate of $10^{\circ} \mathrm{C} \mathrm{min}^{-1}$, using an ultra-dry air atmosphere and a flow rate of $50 \mathrm{~mL} \mathrm{~min}^{-1}$. 
Temperature-programmed reduction (TPR) experiments were conducted using a Zeton Altamira AMI-200 unit. Samples of as-made (dried) alumina and alumina-titania impregnated precursors, either with or without chitosan, were put into a quartz reactor. Circa $50 \mathrm{mg}$ of materials ground to particle size that passed through US Mesh 80 $\left(0.180 \mathrm{~mm}\right.$ ) was heated from 30 to $850^{\circ} \mathrm{C}$ (at a heating rate of $5^{\circ} \mathrm{C} \mathrm{min}^{-1}$ ) under a $30 \mathrm{~mL} \mathrm{~min}^{-1}$ flow of an $\mathrm{Ar} / \mathrm{H}_{2}$ 90/10 (vol/vol) mixture.

Diffuse reflectance infrared Fourier transform spectroscopy (DRIFTS) of various materials was performed by using a Praying Mantis Diffuse Reflectance Accessory coupled to a Frontier Perkin Elmer Spectrometer. Spectra were averaged over 40 scans in a range of $210-4000 \mathrm{~cm}^{-1}$ at a nominal $4 \mathrm{~cm}^{-1}$ resolution.

XPS analyses were performed using a Thermo Scientific K-Alpha X-ray photoelectron spectrometer with a monochromatized AlK $\alpha \mathrm{X}$-ray source $(1487 \mathrm{eV})$. Throughout all measurements, the base pressure in the analysis chamber was $10^{-7}$ mbar. In order to detect and compensate for errors related to charge shift, $\mathrm{O} 1$ s peak at $531.0 \mathrm{eV}$ was employed as internal standard. Narrow scans obtained in different regions located on the samples' surfaces, using a $400 \mu \mathrm{m}$ spot size, were collected at $60 \mathrm{eV}$ pass energy.

2.3. Catalytic Activity Test. Dried materials were sulfided with a $10 \mathrm{vol} . \% \mathrm{H}_{2} \mathrm{~S} / \mathrm{H}_{2}$ mixture at $400^{\circ} \mathrm{C}$ (heating rate, $10^{\circ} \mathrm{C} \mathrm{min}^{-1}$ ) for $2 \mathrm{~h}$. The catalytic activity of the obtained catalysts $(0.2 \mathrm{~g})$ was tested in the dibenzothiophene $(0.3 \mathrm{~g})$ hydrodesulfurization in a batch reactor using $n$-hexadecane $(100 \mathrm{~mL})$ as solvent. Reaction tests were carried out at $320^{\circ} \mathrm{C}$, $72.4 \mathrm{~kg} \mathrm{~cm}^{-2}$, and $1000 \mathrm{rpm}\left(105 \mathrm{rad} \mathrm{s}^{-1}\right)$. Reaction products were analyzed by gas chromatography (Perkin Elmer AutoSystem XL with a flame ionization detector and EconoCap-5 capillary column). Under used operating conditions accuracy of HDS activity determinations is around 5\%.

\section{Results and Discussion}

3.1. Diffuse Reflectance Infrared Fourier Transform Spectra (DRIFTS). Diffuse reflectance infrared Fourier transform spectra (DRIFTS) of the catalysts supported on alumina and alumina-titania are shown in Figures 1 and 2, respectively. Neat chitosan spectrum is included in both figures. The chitosan spectrum shows a big and wide band at $3460 \mathrm{~cm}^{-1}$, corresponding to the stretching vibrations of $\mathrm{OH}$ and $\mathrm{NH}$ groups in the polysaccharide molecule. The overlapped small peaks at 2924 and $2893 \mathrm{~cm}^{-1}$ are associated with the asymmetric and symmetric stretching vibration of the $\mathrm{C}-\mathrm{H}$ bond, in the glycoside ring and in the $-\mathrm{CH}_{2} \mathrm{OH}$ and $-\mathrm{CH}_{3}$ groups [22].

Two little bands not completely defined are observed in the range $1700-1550 \mathrm{~cm}^{-1}$. The band at $1653 \mathrm{~cm}^{-1}$ is attributed to the stretching vibration of the $\mathrm{C}=\mathrm{O}$ group $[22,23]$, whereas the one at $1594 \mathrm{~cm}^{-1}$ is associated with the bending vibration of the NH group $[22,23]$ in the chitosan acetylated units, and it could overlap with the corresponding band to the $\mathrm{NH}_{2}$ group [24] in the nonacetylated units. It is reported [22]

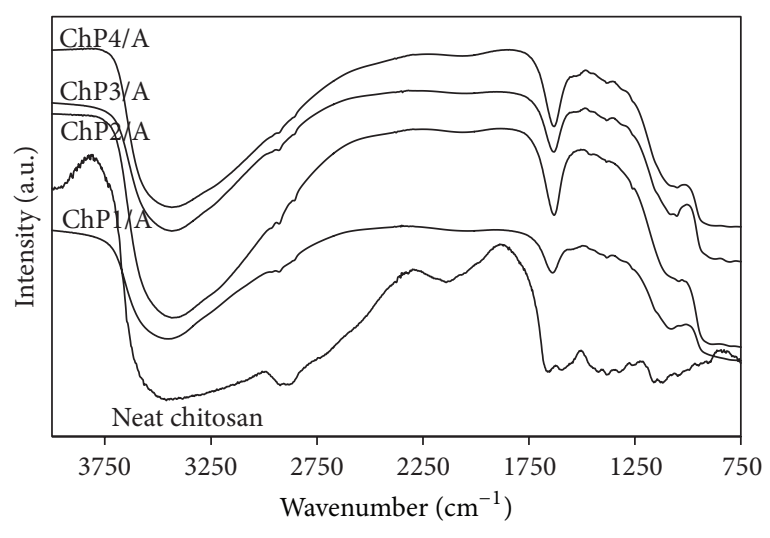

FIGURE 1: Infrared spectra of alumina-supported catalysts.

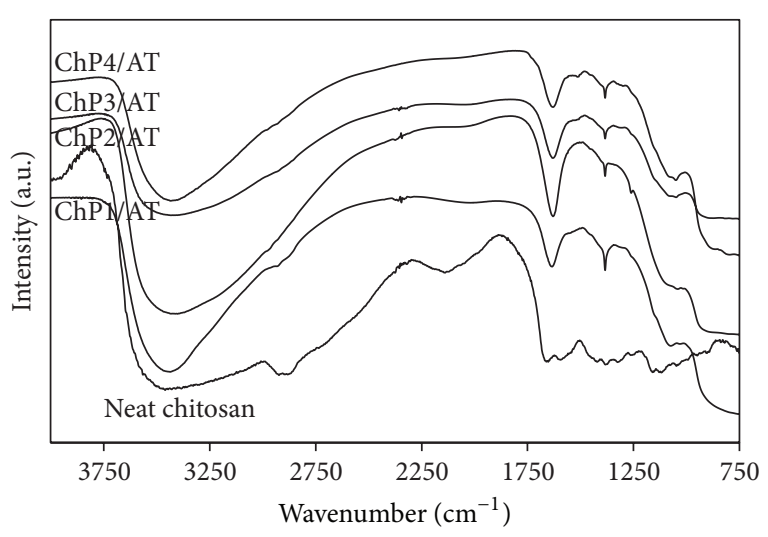

FiguRE 2: Infrared spectra of alumina-titania-supported catalysts.

that these bands may coincide with bands ascribed to $\mathrm{OH}$ groups. In the range of $1450-1250 \mathrm{~cm}^{-1}$, four small bands not completely defined at $1423 \mathrm{~cm}^{-1}$ (C-N stretching coupled with $\mathrm{N}-\mathrm{H}$ plane deformation vibrations [25]), at $1383 \mathrm{~cm}^{-1}$ (C-H asymmetric and symmetric bending vibrations [26] in $\mathrm{CH}_{3}$ groups present in the acetylated monomers of chitosan), at $1325 \mathrm{~cm}^{-1}$ (C-N stretching vibration in the amino group [25]), and at $1263 \mathrm{~cm}^{-1}$ (twisting vibration of $\mathrm{O}-\mathrm{H}$ [27]) are observed. The characteristic bands of chitosan structure corresponding to the $\mathrm{C}-\mathrm{O}-\mathrm{C}$ glycoside bridge and $\mathrm{C}-\mathrm{O}-\mathrm{C}$ bond in the glucose ring are observed in the $1200-900 \mathrm{~cm}^{-1}$ range in registered spectra. The band at $1161 \mathrm{~cm}^{-1}$ [22] may be attributed to the asymmetric stretching vibration of the $\mathrm{C}-\mathrm{O}$ $\mathrm{C}$ glycoside bridge, while the stretching vibration of C-O-C in the biopolymer ring is observed at 1120 and $1048 \mathrm{~cm}^{-1}$ [22].

With regard to the alumina-supported catalysts (Figure 1), the broad bands with maxima in the $3469-3443 \mathrm{~cm}^{-1}$ range are attributed to the overlapped stretching vibration bands of the $\mathrm{OH}$ and $\mathrm{NH}$ groups in chitosan $[25,28]$. These bands are less intense than that corresponding to the pure polysaccharide. It is reported [29] that the decrease in the intensity of the $\mathrm{OH}$ bands on the spectra is due to the interaction of $\mathrm{Al}$ atoms in the alumina support with the oxygen ones of the $\mathrm{OH}$ groups bonded to the glycoside ring of the polysaccharide. With the exception of the ChP1/A 
material, in the spectra of the other materials in the series, a slight red-shift of the overlapped $\mathrm{OH}$ and $\mathrm{NH}$ bands as to those of the chitosan is observed, which could suggest modified intermolecular interactions [29]. The small bands in the $2941-2862 \mathrm{~cm}^{-1}$ range are related to the asymmetric and symmetric stretching vibration of the $\mathrm{C}-\mathrm{H}$ bond [22], as has been mentioned before.

The band registered between 1647 and $1638 \mathrm{~cm}^{-1}$ corresponds to undissociated water molecules [30]. In this region the stretching and deformation vibration bands of the $\mathrm{OH}$ groups of the support also appear [31]; however, because phosphoric acid was used to prepare these materials, the vibrations in the mentioned range could correspond to water molecules associated with phosphate ions $\mathrm{P}-\mathrm{OH}[32$, 33]. Regarding the spectra of materials containing chitosan, in this region the bands of the $\mathrm{OH}$ groups [31] appear along with those corresponding to the Al-O-C bonds [34] produced by interaction between alumina support and the organic molecule. Also, the peak associated with the $\mathrm{NH}_{2}$ group bending vibration disappeared, and a small and wide inflection at lower wavenumbers is observed instead. The shift of this band to $1551 \mathrm{~cm}^{-1}$ may indicate that the amino group is bonded to phosphorus [35] contained in the impregnation solutions and it could have formed complex with nickel through oxygen atoms in the phosphate group. Some inflections in the $1392-1388 \mathrm{~cm}^{-1}$ range could be related to $\mathrm{P}=\mathrm{O}$ bond stretching vibrations [35] in phosphate groups, and the band at $1264 \mathrm{~cm}^{-1}$ could also be assigned to the same vibration $[32,36]$. The bands corresponding to the C-O-C glycoside bridge vanish in the spectra of prepared materials; this fact suggests that chitosan has been hydrolyzed by the phosphoric acid contained in the impregnating solutions. The inflection at $1156 \mathrm{~cm}^{-1}$ in the $\mathrm{ChP} 1 / \mathrm{A}, \mathrm{ChP} 3 / \mathrm{A}$, and ChP4/A materials could be attributed to the $\mathrm{P}-\mathrm{OH}$ stretching vibration [37]. Other peaks appear in the $1092-1040 \mathrm{~cm}^{-1}$ range. The bands at 1092 [37] and $1040 \mathrm{~cm}^{-1}$ [35] are associated with the $\mathrm{P}-\mathrm{OH}$ bond; however, they could also be ascribed to the C-O$\mathrm{C}$ bond in the chitosan ring [25], which could remain after the organic molecule has undergone the phosphorylation process [35]. The bands at 1061 and $1056 \mathrm{~cm}^{-1}$ are related to P-OMo bonds [38]. Finally, bands at 900 and $808 \mathrm{~cm}^{-1}, 871$ and $811 \mathrm{~cm}^{-1}$, and 900 and $814 \mathrm{~cm}^{-1}$, in the ChP2/A, ChP3/A, and $\mathrm{ChP} 4 / \mathrm{A}$ materials, respectively, are attributed to $\mathrm{Mo}=\mathrm{O}$ and Mo-O-Mo stretching vibrations [38].

The infrared spectra of the catalysts supported on alumina-titania (Figure 2) are very similar to those corresponding to alumina-supported catalysts. The broad band in the $3780-2420 \mathrm{~cm}^{-1}$ range corresponds to overlapped stretching vibration bands of $\mathrm{OH}$ and $\mathrm{NH}$ groups [28]. The vibration bands registered between 1653 and $1641 \mathrm{~cm}^{-1}$ are similar to those described for the materials supported on alumina. The band at $1386 \mathrm{~cm}^{-1}$ is attributed to $\mathrm{CH}$ bending [39] and $\mathrm{C}-\mathrm{CH}_{3}$ deformation vibration [39] in the acetylated monomers of the macromolecule. That band vanishes in the ChP4/AT sample most probably due to the fragmentation of the organic molecule and as a result of the interaction of the donor atoms of chitosan with nickel. In the ChP1/AT material, the band at $1097 \mathrm{~cm}^{-1}$ corresponds to stretching

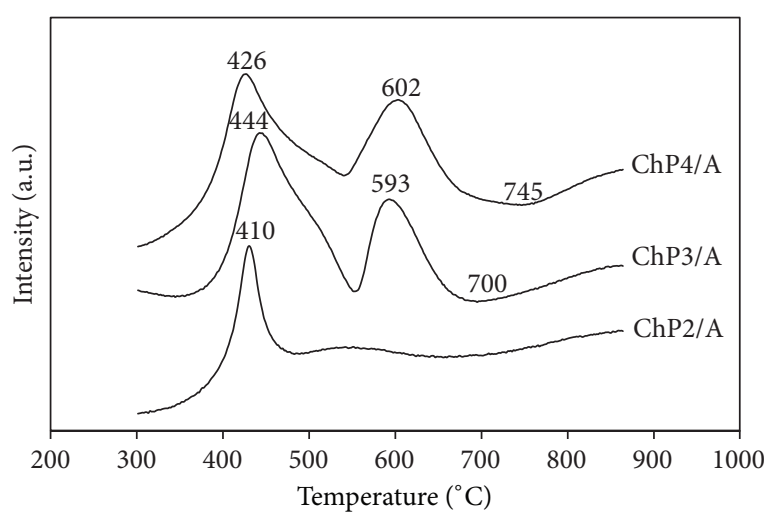

FIGURE 3: TPR profiles of alumina-supported catalysts.

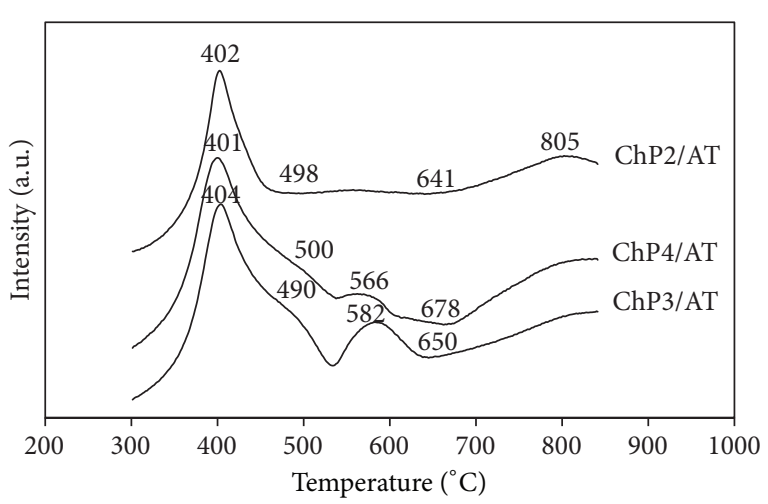

FIGURE 4: TPR profiles of alumina-titania-supported catalysts.

vibrations of the C-O-C bond in the biopolymer ring [28]. However, in samples that have been impregnated with metal solutions with nickel and molybdenum, that band gains intensity and is red-shifted, which could indicate modifications in the chemical environment of the chitosan ring due to the interaction of the donor atoms in the vicinity of the glycosidic bridge.

3.2. Temperature-Programmed Reduction. Figures 3 and 4 show temperature-programmed reduction profiles of catalysts supported on alumina and alumina-titania, respectively. In Figure 3, regarding catalysts supported on alumina, an intense reduction peak with maximum at 444 (ChP3/A) and $426^{\circ} \mathrm{C}(\mathrm{ChP} 4 / \mathrm{A})$ was observed. Those peaks display a shoulder between $\sim 516$ and $\sim 509^{\circ} \mathrm{C}$. These signals are ascribed to the reduction of the octahedral species $\mathrm{Mo}^{6+}$ to $\mathrm{Mo}^{4+}$, which are usually present as polymolybdate structures that weakly interact with the support [1]. The peaks that appear between 593 and $602^{\circ} \mathrm{C}$ could be ascribed to the reduction of $\mathrm{Ni}^{2+}$ species most probably originated by the metal complex formed between nickel and chitosan which led to segregated nickel species. The TPR profiles of those materials also showed the formation of a broad peak at higher 
temperatures, in the $700-745^{\circ} \mathrm{C}$ range that could be attributed to the reduction of $\mathrm{Mo}^{6+}$ tetrahedral species strongly bonded to the support, to $\mathrm{Mo}^{0}$ ones [1].

The profile of the ChP2/A reference material shows a peak with maximum at $410^{\circ} \mathrm{C}$; this peak is associated with the reduction of $\mathrm{Mo}^{6+}$ species to $\mathrm{Mo}^{4+}$ ones. In the $462-$ $632^{\circ} \mathrm{C}$ range a broad and less intense signal appears, which could be assigned to the reduction of $\mathrm{Ni}^{2+}$ to $\mathrm{Ni}^{0}$ species. The peak with maximum at $820^{\circ} \mathrm{C}$ may correspond to reduction of tetrahedral $\mathrm{Mo}^{4+}$ species strongly attached to the support [1].

The TPR profiles of the catalysts supported on aluminatitania (Figure 4) are very similar to those supported on alumina (Figure 3), but in that case the peaks appear at lower temperatures. The catalysts $\mathrm{ChP} 3 / \mathrm{AT}$ and $\mathrm{ChP} 4 / \mathrm{AT}$ display an intense peak between 404 and $401^{\circ} \mathrm{C}$, and a shoulder between $\sim 490$ and $\sim 500^{\circ} \mathrm{C}$. Those signals are attributed to the reduction of octahedral $\mathrm{Mo}^{6+}$ species to $\mathrm{Mo}^{4+}[1]$. The peaks that appear between 582 and $566^{\circ} \mathrm{C}$ could correspond to $\mathrm{Ni}^{2+}$ species reduction. The broad signal in the $650-678^{\circ} \mathrm{C}$ range could be attributed to reduction of $\mathrm{Mo}^{4+}$ tetrahedral species strongly bonded to the support, to $\mathrm{Mo}^{0}$ ones. The ChP2/AT reference material profile shows a wide peak with maximum at $402^{\circ} \mathrm{C}$; this peak is associated with reduction of $\mathrm{Mo}^{6+}$ species to $\mathrm{Mo}^{4+}$ ones. In the $498-641^{\circ} \mathrm{C}$ range a broad and less intense signal appears, which could be related to reduction of $\mathrm{Ni}^{2+}$ to $\mathrm{Ni}^{0}$ species. The peak at higher temperatures with maximum at $805^{\circ} \mathrm{C}$ may correspond to reduction of tetrahedral $\mathrm{Mo}^{4+}$ species strongly attached to the support [1].

With regard to the order of impregnation, the catalyst that was first impregnated with the ChP solution (ChP3/AT) was reduced at higher temperature than the material that was first impregnated with NiMoP solution (ChP4/AT). This suggests that the complex could consist of phosphorylated chitosan and nickel. It is reported that chitosan could be phosphorylated when it reacts with $\mathrm{H}_{3} \mathrm{PO}_{4} / \mathrm{Et}_{3} \mathrm{PO}_{4} / \mathrm{P}_{2} \mathrm{O}_{5} /$ hexanol [35]; in this process phosphorus bonds chitosan through the $\mathrm{OH}$ and $\mathrm{NH}_{2}$ groups of the macromolecule. Chitosan also forms complexes with $\mathrm{Ni}^{2+}[40,41]$ through amino groups in the polysaccharide molecule. In this work, we used $\mathrm{H}_{3} \mathrm{PO}_{4}$ to prepare chitosan solutions; thus, nickel could be linked to phosphorylated chitosan through phosphorus atoms bonded to amino and $\mathrm{OH}$ groups in the organic additive. Chitosan is a crystalline polymer in its natural state [42]; however, the phosphorylation process decomposes the crystalline structure of chitosan [37]. Consequently, the formed complex is less stable in the ChP4/AT material than in the ChP3/AT one, which is reasonable because the phosphorous-chitosan complex could interact with most acidic hydroxyl groups of the alumina support and with surface acid Lewis sites as well, which in turn could avoid strong interaction between the polymolybdate species formed on the surface of the support. In this context, some of us reported that organic additives with donor atoms such as ethylene glycol could act as nucleophiles on the Lewis acid sites of the support [21] resulting in chemisorbed glycol molecules over $\mathrm{Al}^{3+}$ sites, which would prevent strong interactions between the active metallic phases and the support.

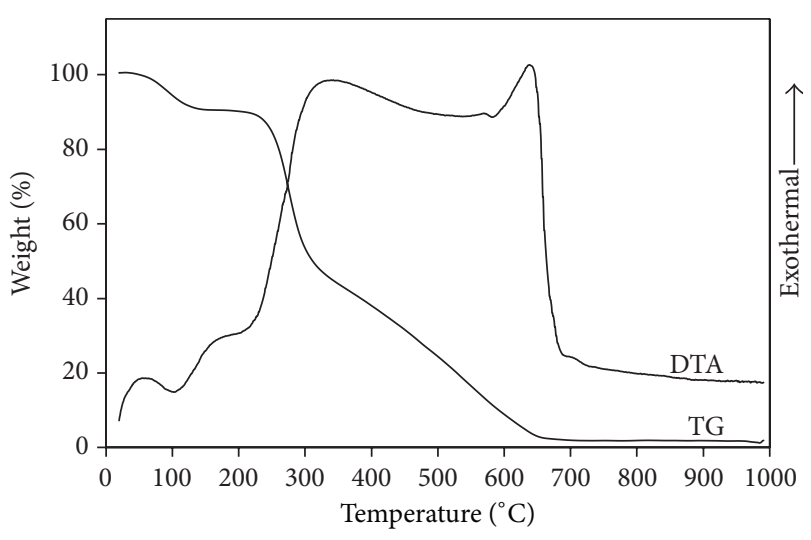

FIgURE 5: Thermal analysis of chitosan.

\subsection{Thermal Analysis}

3.3.1. Thermal Analysis of Chitosan. Figure 5 shows the TG and DTA curves obtained by the thermal degradation of chitosan at $10^{\circ} \mathrm{C} \mathrm{min}^{-1}$ heating rate. The TG curve shows three thermal events; however, in the DTA curve at least five thermal events, endothermic and exothermic, are observed up to $700^{\circ} \mathrm{C}$. Those thermal events are associated with the dehydration and thermal degradation processes, including depolymerization and decomposition stages of chitosan and char combustion.

The first endothermic peak takes place between 60 and $170^{\circ} \mathrm{C}$, with minimum at $104^{\circ} \mathrm{C}$. Weight loss of $10 \%$ is attributed to evaporation of physisorbed water in the chitosan structure. The second thermal event starts at 245 and finishes at $650^{\circ} \mathrm{C}$ with related weight loss of $80 \%$ and is assigned to vaporization and burning of volatile compounds coming from thermal degradation of chitosan structure. In this regard, it is reported that the pyrolysis of polysaccharidelike structures generally starts with the split of the glycosidic linkages and is followed by the decomposition of the sixmembered-ring moiety, which affords several organic compounds in which $\mathrm{C}_{2}, \mathrm{C}_{3}$, and $\mathrm{C}_{6}$ fragments predominate [43]. In this regard, López and coworkers [43] reported a peak in the DTA which appears in the $387-471^{\circ} \mathrm{C}$ range and is connected with residual cross-linked degradation of chitosan. In this line, Georgieva et al. [44] recently reported a similar exothermic peak; however, in their study that peak is positioned at $544^{\circ} \mathrm{C}$. It is important to point out that Georgieva et al. [44] did not discuss any other peak above that temperature. In the same line, the group of López et al. [43] only reports the $\mathrm{TG}$ from room temperature to $600^{\circ} \mathrm{C}$. In our study, besides the peak at $569^{\circ} \mathrm{C}$, we observed an exothermic peak which occurs at $638^{\circ} \mathrm{C}$. In this case we attributed that signal to gasification of char from chitosan, which could stem from recombination and reaction of compounds formed in the gas phase in previous thermal events. In this regard, the group of Aburto et al. [45] has reported that DTA of pectin, which is an analogous compound to chitosan, shows an exothermic peak above $600^{\circ} \mathrm{C}$, which represents a thermooxidative process of residual products previously formed. Finally, in our case, the sharpness of that exothermic peak 


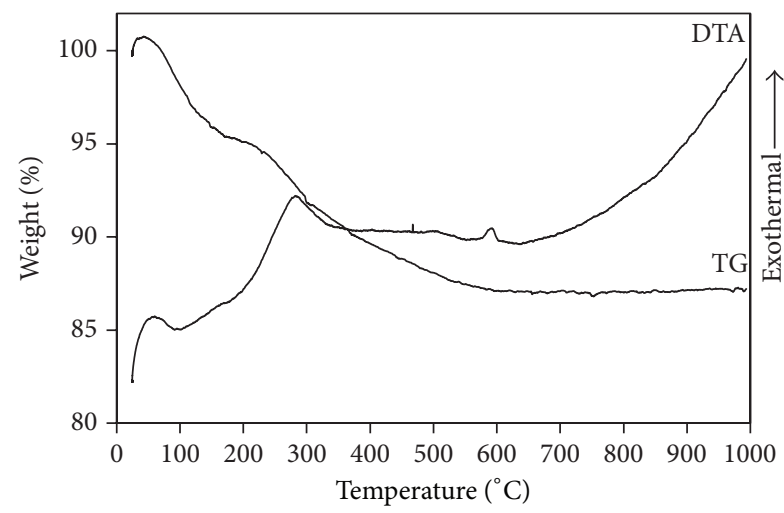

(a)

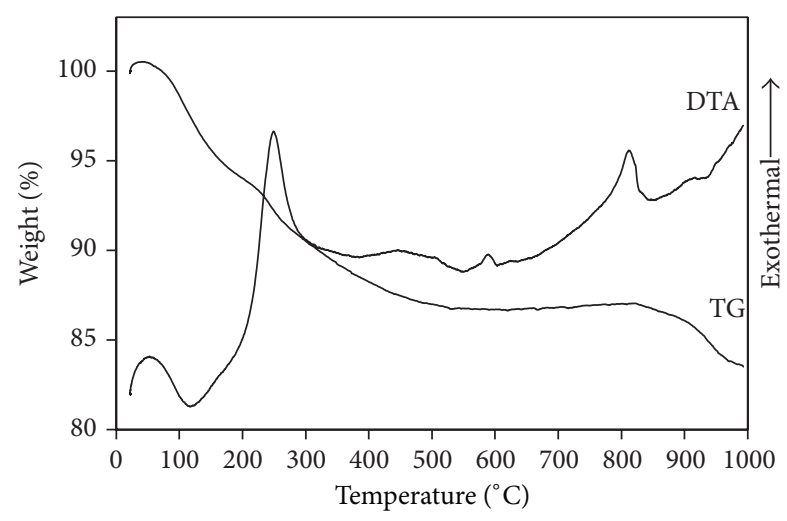

(c)

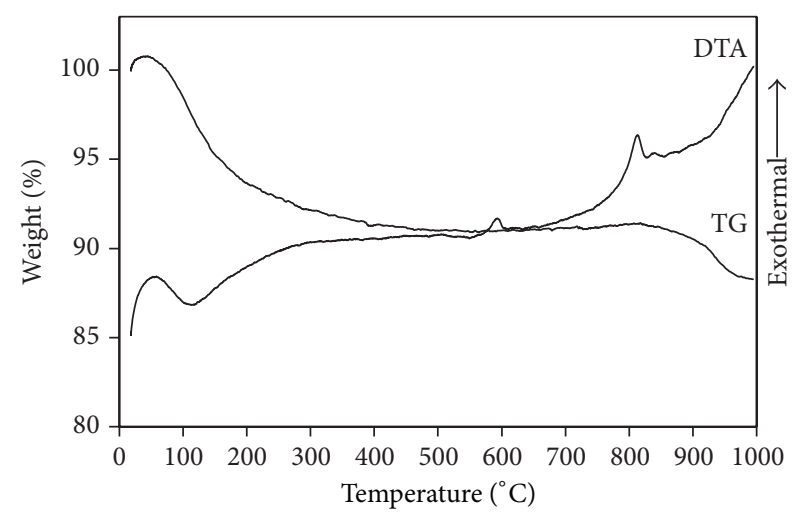

(b)

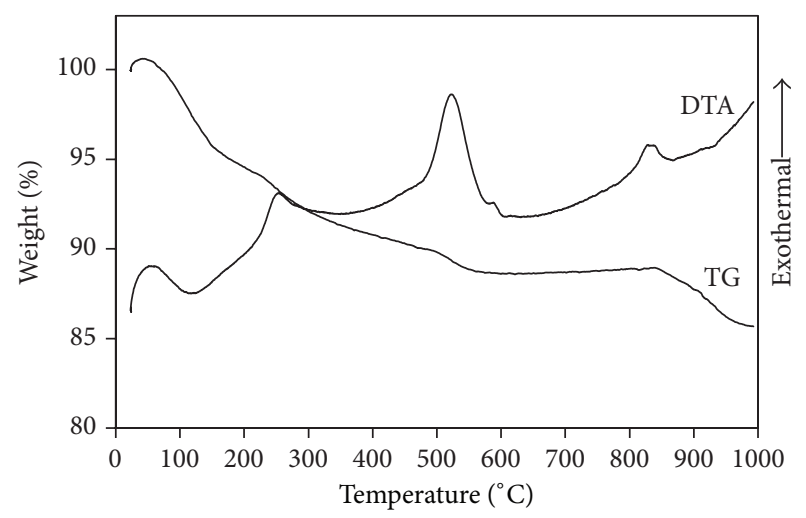

(d)

FiguRE 6: TG-DTA profiles of alumina-supported materials: (a) ChP1/A, (b) ChP2/A, (c) ChP3/A, and (d) ChP4/A.

indicated that nature of bonds present in those compounds is a similar one to another in terms of energy.

\subsubsection{Thermal Analysis of Materials Supported on Alumina.} Thermal analysis (TGA-DTA) results of the noncalcined materials supported on alumina (dried at $120^{\circ} \mathrm{C}$ ) are shown in Figures 6(a)-6(d). Thermal gravimetric analysis revealed different events associated with physisorbed water evaporation, decomposition of the organic additive (except for sample ChP2/A), and molybdenum trioxide sublimation (except for sample ChP1/A). Figure 6(a) shows the TG-DTA profiles of chitosan impregnated on the alumina support (ChP1/A). The first endothermic peak takes place between 65 and $180^{\circ} \mathrm{C}$, with minimum at $95^{\circ} \mathrm{C}$. A corresponding weight loss of $5 \%$ is attributed to evaporation of physisorbed water in the chitosan structure. After that dehydration process, a weight loss of $8 \%$ occurs around $240^{\circ} \mathrm{C}$ with maximal degradation at $290^{\circ} \mathrm{C}$ and continued and prolonged up to $600^{\circ} \mathrm{C}$. In the same interval, the DTA displays one exothermic peak centered at $290^{\circ} \mathrm{C}$, which corresponds to chitosan decomposition; that peak is located at lower temperature than that of neat chitosan. This shift in the degradation temperature could be rationalized in terms of the interactions among the $\mathrm{NH}_{2}$ and hydroxyl groups of the chitosan with the acid sites of the alumina, which favor the cracking of some bonds or functional groups, structural depolymerization, and chains breaking along the polysaccharide structure. The TG registers a weight loss in this range; however, in the DTA only slight changes in evolved energy are observed. This behavior could be associated with the presence of a complex set of reactions, such as chemical recombination processes in the gas phase. Finally, an exothermic peak appears at $590^{\circ} \mathrm{C}$, which may be the result of a structural rearrangement of the alumina induced by the addition of phosphorus to the network.

Figure 6(b) shows the TG-DTA profiles of the NiMoP solution impregnated on the alumina support (ChP2/A). The DTA curve displays an endothermic peak between 56 and $167^{\circ} \mathrm{C}$, with minimum at $111^{\circ} \mathrm{C}$, which is attributed to evaporation of physisorbed water in the material, with corresponding weight loss of about $6 \%$. After that dehydration process, we observed a prolonged weight loss of $3 \%$ up to $500^{\circ} \mathrm{C}$. Finally, there is an exothermic peak at temperature higher than $800^{\circ} \mathrm{C}$ which is associated with nickel aluminate formation [21]. The endothermic inflection in TG profile could correspond to $\mathrm{MoO}_{3}$ sublimation [46]. Both thermal events are also present in samples $\mathrm{ChP} 3 / \mathrm{A}$ and $\mathrm{ChP} 4 / \mathrm{A}$ (Figures 6(c) and 6(d), resp.).

The TGA-DTA of samples ChP3/A and ChP4/A, in which we varied the order of chitosan addition, are presented in Figures 6(c) and 6(d). From those profiles, it is clear that the addition order induces important changes in the degradation of chitosan. The first stage of weight loss is 
related to evaporation of water physisorbed on the materials. That weight loss represents about $4-6 \%$ and takes place in the range of $49-210^{\circ} \mathrm{C}$, which reaches a maximum at $110^{\circ} \mathrm{C}$. After that evaporation process, several exothermic events are clearly distinguished, which correspond to chitosan decomposition in the $210-590^{\circ} \mathrm{C}$ range. However, profiles of samples $\mathrm{ChP} 3 / \mathrm{A}$ and $\mathrm{ChP} 4 / \mathrm{A}$ exhibit exothermic peaks with significant differences in intensity and shape. Those processes are exothermic and are attributed to depolymerization of polymeric chains, which includes pyranose rings decomposition [39], and ring opening reactions [28]. In both cases, the polysaccharide degradation starts at lower temperature than in the ChP1/A sample. Nevertheless, the first exothermic peak of that process is more intense in $\mathrm{ChP} 3 / \mathrm{A}$ than in ChP4/A, which clearly indicates that the order of chitosan addition influences the interaction of the lone electron pairs of nitrogen and oxygen atoms in the chitosan structure with the surface acid sites of alumina and the nickel atoms. In the former sample (ChP3/A) chitosan was first added to the support and, apparently, acid sites on alumina $\left(\mathrm{Al}^{3+}\right)$ promote more efficient degradation than in the case of the latter material. The thermal profile of $\mathrm{ChP} 3 / \mathrm{A}$ sample closely resembles that of the $\mathrm{ChP1/A}$ one. In this regard, some of us recently reported a study in which we evidenced (by DRIFT) the chemical interaction between oxygen atoms coming from hydroxyl groups of ethylene glycol and $\mathrm{Al}^{3+}$ coordinatively unsaturated sites (CUS) on the alumina surface [21]. In other studies, van Veen et al. [47] reported formation of Al-O$\mathrm{C}$ bonds from chemical interaction between acetylacetonate and CUS $\left(\mathrm{Al}^{+3}\right)$ on the alumina surface. Also, Ramis et al. [48] reported similar results founding that various alcohols are adsorbed over titania through Lewis acid sites present on the $\mathrm{TiO}_{2}$ surface.

On the other hand, thermal profile of the ChP4/A sample presents significant differences in the intensity and shape of the registered exothermic peaks, as to those corresponding to the rest of materials. The mentioned thermal profile looks like that of neat chitosan (Figure 5). This could result from weaker interaction between $\mathrm{OH}$ and $\mathrm{NH}_{2}$ groups of chitosan with the acid sites on the alumina support. In this line, different research groups have reported interacting forces between the lone electron pair of nitrogen atoms of chitosan and nickel $[40,41,49]$, where only a small number of amino groups remain free. The final weight loss associated with chitosan decomposition in samples ChP3/A and ChP4/A is about 6\% and $4 \%$, respectively.

3.3.3. Thermal Analysis of Catalysts Supported on AluminaTitania. Figures 7(a)-7(d) show TG-DTA curves of the noncalcined materials supported on alumina-titania. The thermal gravimetric analysis displayed events related to evaporation of physisorbed water, decomposition of the organic additive (except for the sample without chitosan), and molybdenum trioxide sublimation for samples prepared with NiMoP formulation. Figure 7(a) shows the TG-DTA profile of chitosan impregnated on the alumina-titania support (ChP1/AT). The first endothermic peak takes place between 60 and $190^{\circ} \mathrm{C}$, with minimum at $95^{\circ} \mathrm{C}$. A weight loss of $5 \%$ is assigned to water evaporation. After that dehydration, an exothermic peak starts around $190^{\circ} \mathrm{C}$ with maximal degradation at $290^{\circ} \mathrm{C}$, ending up to $600^{\circ} \mathrm{C}$. For the ChP2/AT sample, as shown in the corresponding DTA curve (Figure 7(b)), the endothermic effect shows that until $240^{\circ} \mathrm{C}$ only evaporation of physisorbed water takes place. Afterwards, there is a domain of stability up to $610^{\circ} \mathrm{C}$, where an exothermic peak not associated with weight loss but more probably due to structural rearrangement of some metallic phases was identified. The last thermal event starts at 800 and continues to $1000^{\circ} \mathrm{C}$, which could be related to nickel aluminate formation [21] and to $\mathrm{MoO}_{3}$ sublimation [46]. In the aforementioned high-temperature range, similar thermal profiles are seen for $\mathrm{ChP} 3 / \mathrm{AT}$ and ChP4/AT samples (Figures 7(c) and 7(d), resp.).

With regard to the ChP3/AT and ChP4/AT samples, the first endothermic process $\left(50-190^{\circ} \mathrm{C}\right)$ initiates with weight loss of about $5 \%$ and corresponds to physisorbed water. In the next thermal event, the sample ChP3/AT shows a peak that starts at 190 and ends up at $350^{\circ} \mathrm{C}$. That process is exothermic and takes place through deacetylation and depolymerization of the polymeric chains (rupture of glycosidic bonds). Then, there is a peak that starts at 350 and ends at $550^{\circ} \mathrm{C}$ with an associated weight loss of $4 \%$. That peak could be associated with pyranose ring decomposition [39] and ring opening reactions [28]. Apparently, in that sample, chitosan degradation is not as efficient as in the ChP3/A sample, which could be due to weaker interaction of $\mathrm{OH}$ and $\mathrm{NH}_{2}$ groups in the organic additive with the support or nickel atoms. As regards the ChP4/AT sample, the first exothermic peak is less intense than that of the $\mathrm{ChP} 3 / \mathrm{AT}$ one, starting at 170 and ending up at $350^{\circ} \mathrm{C}$, with an associated weight loss of $4 \%$. In that case, the peak is assigned to deacetylation process and splitting of glycosidic linkages. Then, we observe another exothermic peak that is more intense than that of the ChP3/AT sample; another important characteristic of that peak is that it appears to be more similar to signals that arose from neat chitosan DTA analysis (Figure 5).

3.4. X-Ray Photoelectron Spectroscopy (XPS). In order to try to explain the found differences in chitosan degradation from our TG-DTA studies, XPS analyses were performed on the $\mathrm{ChP} 4 / \mathrm{A}$ and $\mathrm{ChP} 4 / \mathrm{AT}$ samples, which were previously treated at $350^{\circ} \mathrm{C}$ under air. The XPS spectrum of the Mo(3d) energy region obtained for the treated samples ChP4/A and ChP4/AT (Figure 8) displays two well-defined spectral lines (at 232.47 and $235.59 \mathrm{eV}$ and at 232.38 and $235.52 \mathrm{eV}$, for ChP4/A and ChP4/AT, resp.) which are characteristics of $\operatorname{Mo}\left(3 d_{5 / 2,3 / 2}\right)$ spin-orbit components of polymolybdates in formal $6^{+}$oxidation state. Although the presence of organic additives could lead to interactions between carbon and molybdenum, in our case, the observed binding energy (BE) values do not show significant differences, as to those reported in the literature [50-52].

Figure 9 shows the $\mathrm{C}(1 \mathrm{~s})$ energy region XPS spectra for the ChP4/A and ChP4/AT samples, in which we observed an asymmetric peak centered at 284.6 and $284.51 \mathrm{eV}$ for the alumina- and alumina-titania-supported sample, respectively. Deconvolution of corresponding C 1s XPS spectra 


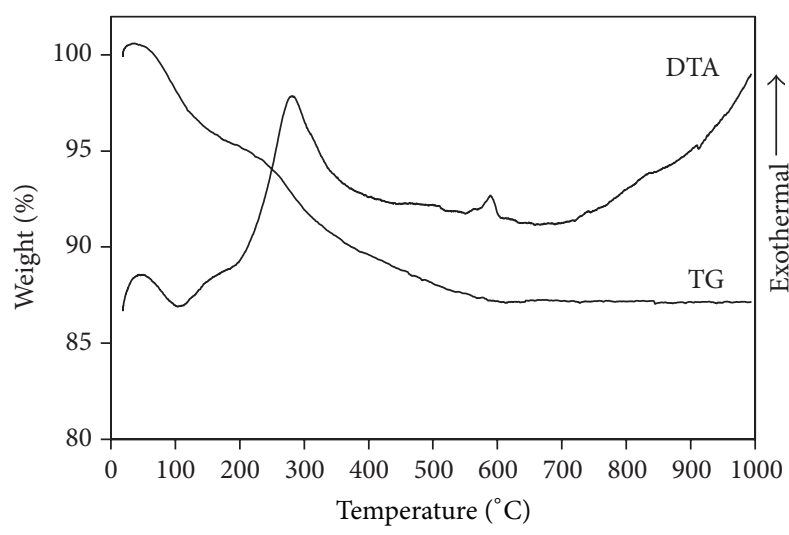

(a)

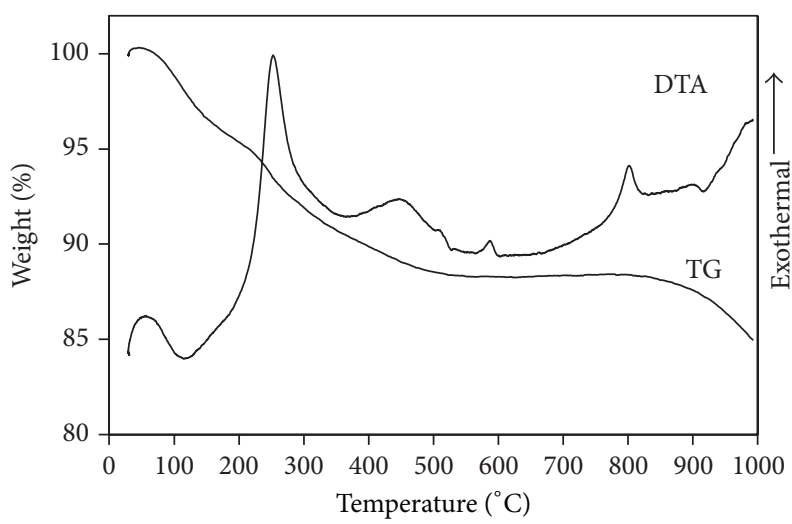

(c)

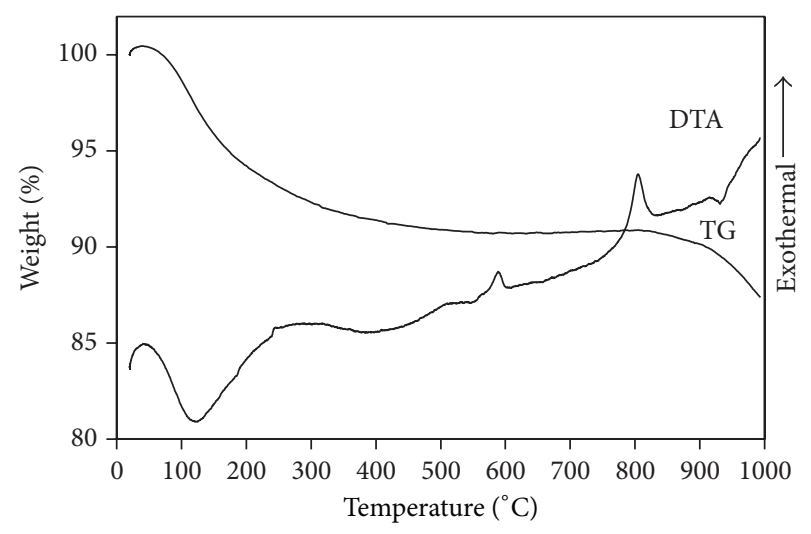

(b)

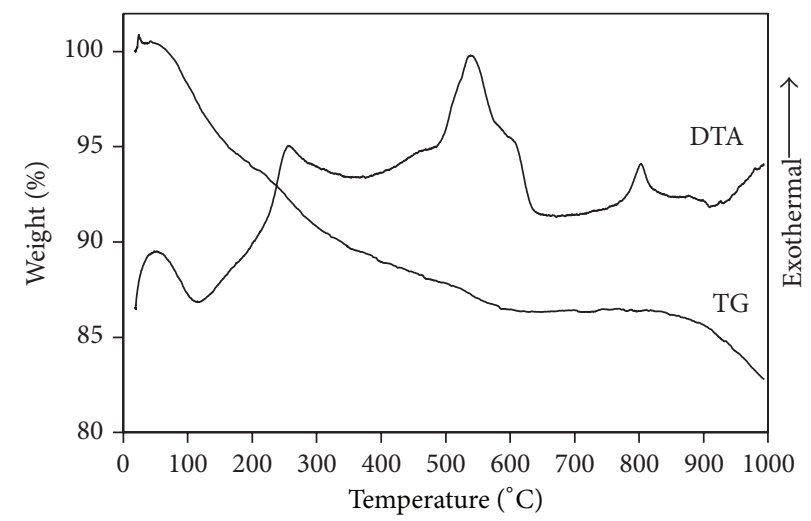

(d)

FIgURE 7: TG-DTA profiles of alumina-titania-supported materials: (a) ChP1/AT, (b) ChP2/AT, (c) ChP3/AT, and (d) ChP4/AT.

TABle 2: Assignment of main spectral bands, as based on their binding energies (BE), of carbon surface species on samples ChP4/A and $\mathrm{ChP} 4 / \mathrm{AT}$ calcined at $350^{\circ} \mathrm{C}$ under air.

\begin{tabular}{lccccc}
\hline \multirow{2}{*}{ Element } & \multicolumn{2}{c}{ ChP4/A } & \multicolumn{2}{c}{ ChP4/AT } & \multirow{2}{*}{ Chemical bonds } \\
& BE $(\mathrm{eV})$ & Weight\% & BE (eV) & Weight\% & \\
\hline C 1s & 284.46 & 55.4 & 284.51 & 69.8 & C-C \\
C 1s & 285.76 & 35.8 & 285.89 & 24.9 & C-N or C-O \\
C 1s & 288.2 & 8.9 & 288.38 & 5.4 & C=O \\
\hline
\end{tabular}

produced three different profiles comprising spectral line with maxima at $284.46,285.76$, and $288.2 \mathrm{eV}$ for $\mathrm{ChP} 4 / \mathrm{A}$, and at 284.51, 285.89, and $288.38 \mathrm{eV}$ for ChP4/AT.

Table 2 summarizes bands identified in the aforementioned XPS spectra and the weighed contribution (\%) of various registered surface species on the $\mathrm{ChP} 4 / \mathrm{A}$ and $\mathrm{ChP} 4 / \mathrm{AT}$ samples. The main C 1s peak at $\sim 285.0 \mathrm{eV}$ corresponds to carbon $(\mathrm{C}-\mathrm{C})$ due to the chitosan backbone decomposition. However, it is worth mentioning that the band could also comprise adventitious carbon. The peak at $\sim 286.0 \mathrm{eV}$ was assigned to $\mathrm{C}-\mathrm{O}$ or $\mathrm{C}-\mathrm{OH}$ bonds, but it could also result from C-N fragments of amine group. Finally, the signal circa $288.3 \mathrm{eV}$ is ascribed to carboxyl groups, most probably from acetyl fragments originated by the deacetylation process [53, 54]. With regard to weighed contributions from different carbon-derived types, sample ChP4/AT revealed more surface carbonaceous species and fewer oxygen- and nitrogencontaining ones, as to the ChP4/A material; apparently, interaction between chitosan and the binary alumina-titania carrier is weaker than that with the alumina substrate, which allowed higher amount of residual cross-linkages from chitosan in the former. It is worth mentioning that our XPS results agreed with those obtained by TGA-DTA experiments.

3.5. HDS Reaction Tests. Catalysts supported on alumina and alumina-titania containing nickel, molybdenum, phosphorus, and chitosan were sulfided and then tested in the dibenzothiophene hydrodesulfurization. Corresponding materials without chitosan (ChP2/A and ChP2/AT) were used as references in each series, respectively. Determined pseudo firstorder kinetic constants are presented in Figure 10. Aluminasupported formulations are most active ones, where the highest HDS activity was obtained with the ChP3/A catalyst (34\% larger than that of the reference ChP2/A). In the opposite, the ChP4/A solid had the lowest activity, representing 37\% of that obtained over the ChP3/A material. On the other hand, regarding the alumina-titania-supported series, the highest HDS activity was observed over the ChP4/AT solid, being around 23\% higher than that of the reference ChP2/AT 


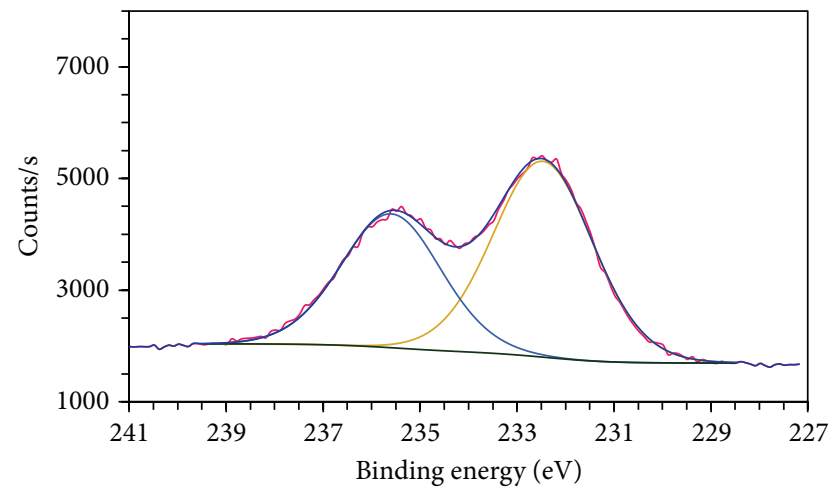

(a)

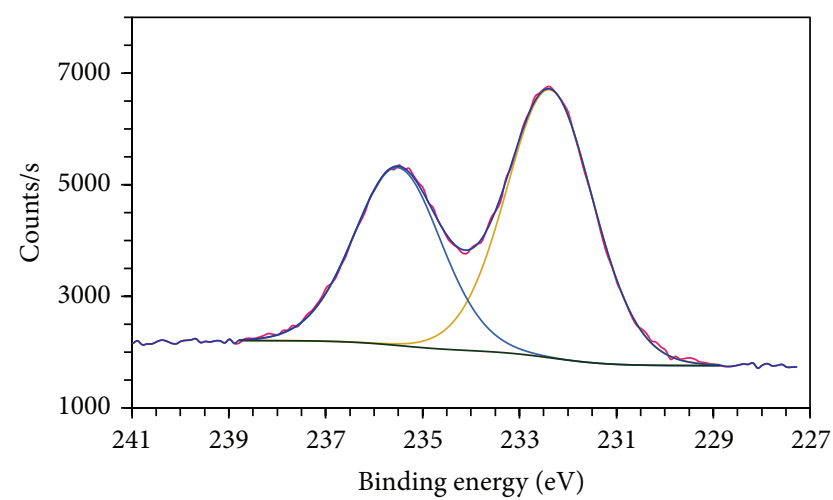

(b)

FIgURE 8: XPS Mo(3d) spectra obtained for (a) ChP4/A and (b) ChP4/AT (treated at $350^{\circ} \mathrm{C}$ under air).

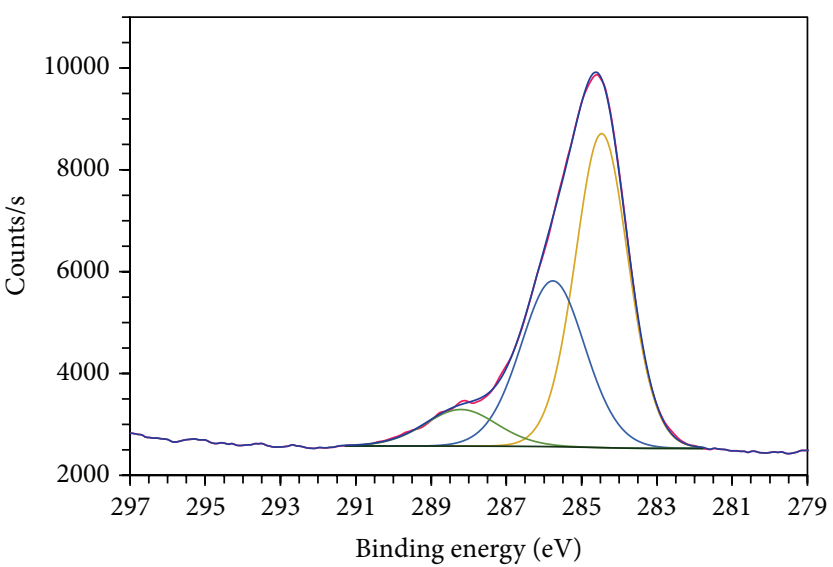

(a)

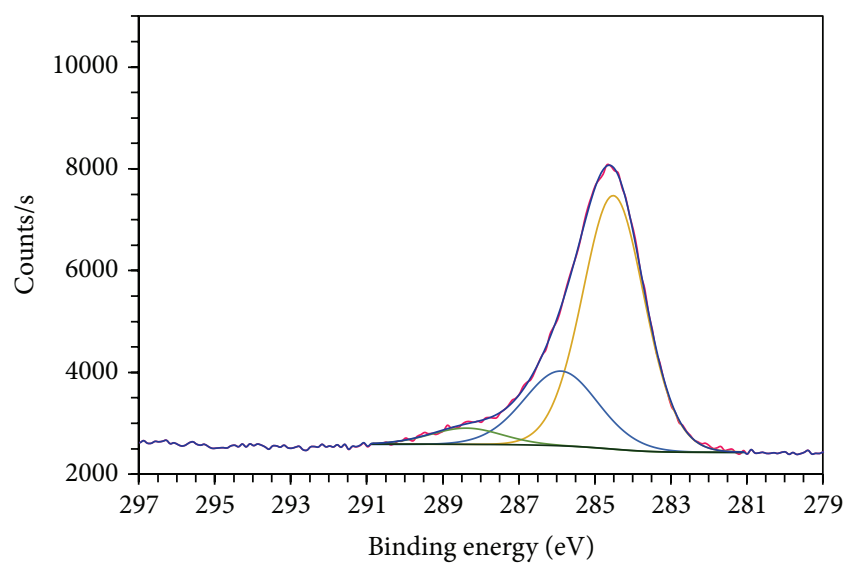

(b)

Figure 9: XPS C 1s spectra obtained for samples (a) ChP4/A and (b) ChP4/AT (treated at $350^{\circ} \mathrm{C}$ under air).

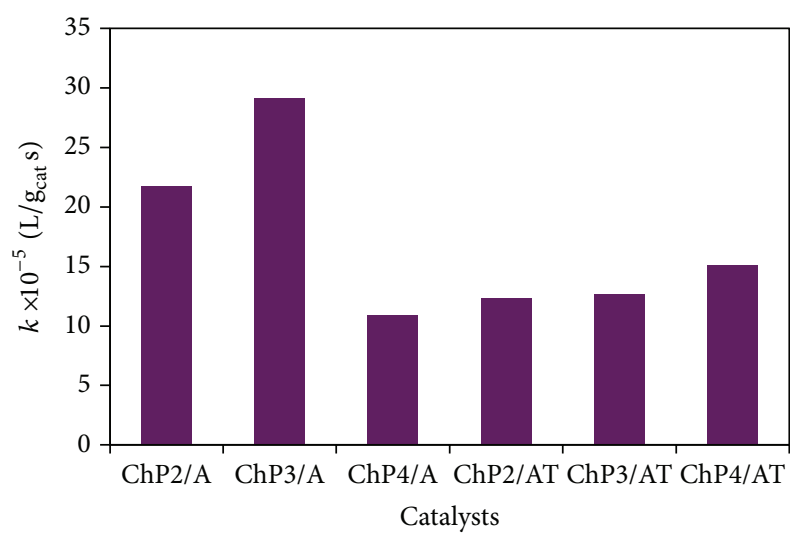

FIGURE 10: Pseudo first-order kinetic constant (DBT HDS) over various sulfided catalysts. Operating conditions: batch reactor, $T$ $=320^{\circ} \mathrm{C}, P=72.4 \mathrm{~kg} / \mathrm{cm}^{2}, n$-hexadecane as solvent, and $1000 \mathrm{rpm}$ (105 rad/s) mixing speed.

sample, whereas the ChP3/AT formulation did not show significant improvement, as compared to that of the reference material.
The product distribution at 50\% DBT conversion over various tested sulfided catalysts is shown in Figure 11. With respect to the series of alumina-supported materials, the obtained products were biphenyl (BF, 77-81.4\%), cyclohexylbenzene (CHB, 15-19\%), partially hydrogenated dibenzothiophene (tetrahydrodibenzothiophene, THDBT, 3.2-4\%), and trace amounts of bicyclohexane $(\mathrm{BCH}, 0.4-0.6 \%)$, the last being just observed over the $\mathrm{ChP} 2 / \mathrm{A}$ and $\mathrm{ChP} 3 / \mathrm{A}$ materials. With regard to the series of catalysts with alumina-titania carrier, the obtained products were BF $(70-88.6 \%)$, CHB (8.8-25\%), and small amounts of THDBT $(2.6-4 \%)$ and BCH (1\%). It is important to point out that THDBT and $\mathrm{BCH}$ were not obtained over the $\mathrm{ChP} 3 / \mathrm{AT}$ catalyst, and $\mathrm{BCH}$ was not observed over the ChP4/AT one.

Clearly, the HDS reaction over both series of catalysts took place preferably through the direct desulfurization (DDS) pathway; however, small amounts of products obtained by hydrogenation (HYD) were also identified. Over the alumina-supported catalysts series biphenyl production was slightly higher (3.7\% increase) in presence of the $\mathrm{ChP} 3 / \mathrm{A}$ catalyst than with the ChP4/A one, while the selectivity to $\mathrm{CHB}$ and THDBT by the hydrogenation pathway diminished 


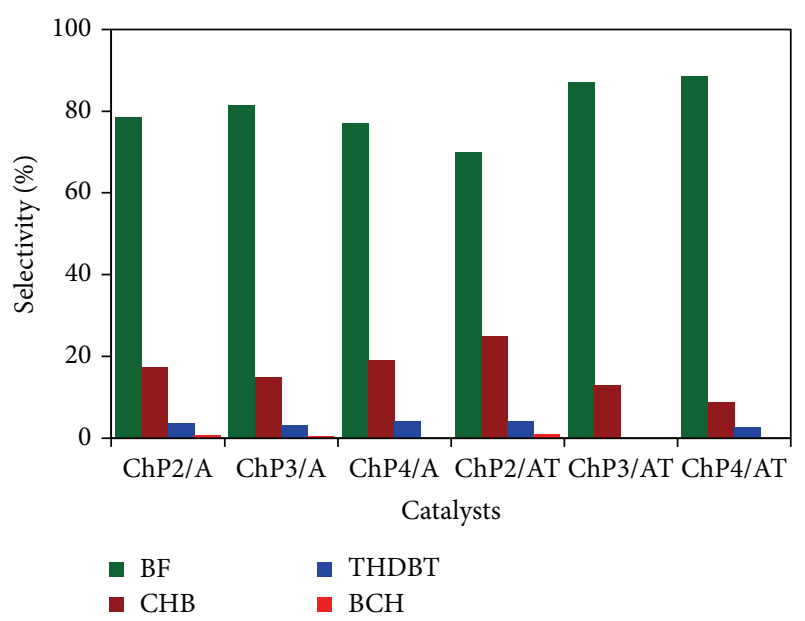

FIGURE 11: Product distribution (DBT HDS) over various sulfided catalysts.

by $13 \%$, as compared to the reference catalyst. With regard to the alumina-titania-supported materials series, biphenyl production was increased over the catalysts impregnated with chitosan, as to that of the reference catalyst. Among each series, the ChP3/A and ChP4/AT materials were the most active in DBT HDS and also displayed the highest selectivity to biphenyl formation.

Bataille et al. [19] reported that coordinatively unsaturated sites located on $\mathrm{MoS}_{2}$ slabs edge constitute the active center for hydrogenolysis reactions whereas adsorption and hydrogenation of aromatic rings take place on adjacent unsaturated Mo atoms with specific chemical environment. That theory implies that the HDS catalyst active phase comprises two kinds of sites for the HDS of DBT-type compounds; one catalyzes the $\mathrm{S}$ direct removal (hydrogenolysis site) whereas the other favors hydrogenation steps. Ramírez et al. [6] reported that, in the DBT hydrodesulfurization, the activity of NiMo catalysts increases with $\mathrm{Ti}$ content; however, the activity of materials with low titanium content is very similar to that of the catalyst with alumina carrier; thus, the HDS increases only over Ti-rich formulations. They also found that, for all studied compositions, direct desulfurization is the preferred pathway in the DBT hydrodesulfurization over titania-containing catalysts. In our case, the $\mathrm{TiO}_{2}$ content is $10 \mathrm{wt} \%$; however, the formulations also comprise phosphorus and, apparently, the effect of the latter is more significant than that induced by titania addition, since the series of alumina-supported catalysts was more active than that with alumina-titania carrier. In this line, phosphorus addition in the catalysts affects not only the active component structure but also the reduction-sulfidation of Ni species. Those authors [6] argued that $\mathrm{AlPO}_{4}$ formed on the catalyst surface weakens the interaction between $\mathrm{Ni}$ and the alumina substrate, resulting in formation of enhanced amount of sulfided $\mathrm{Ni}$ species; nonetheless, excessive phosphorus contents have negative effect on the $\mathrm{NiMoP} / \mathrm{Al}_{2} \mathrm{O}_{3}$ catalysts performance. Finally, another important factor that could contribute to the improved performance of alumina-supported catalysts is that in our case $\mathrm{Al}_{2} \mathrm{O}_{3}$ has a higher surface area than the alumina-titania mixed substrate, which could lead to active sites being better distributed by enhanced sulfides dispersion. On the other hand, Xiang et al. [55] reported that the proper phosphorus content (1.2 wt\%) in NiMoP catalysts was reflected in enhanced $\mathrm{MoS}_{2}$ dispersion by increasing stacking number; meanwhile slab length is diminished, resulting in increased HYD selectivity (DBT HDS). In another study, Gutiérrez and Klimova [56] tested (DBT HDS) a series of NiMo catalysts supported on different materials and they found that the selectivity is ruled, in the first instance, by the morphology of dibenzothiophenic compounds and, at a minor extent, by the $\mathrm{MoS}_{2}$ stacking degree. They also reported that hydrogenation is the preferred pathway in 4,6-DMDBT HDS (4,6-dimethyl-DBT), whereas DBT reacts either by DDS or by HYD without any intrinsic preference for any reaction pathway. They also identified two types of NiMoS phases, depending on the stacking degree, and indicated that only on highly stacked $\mathrm{MoS}_{2}$-like clusters the HYD activity of the catalysts does increase. In our study, DDS is the preferred reaction route, which is in line with the findings of Gutiérrez and Klimova [56]. With regard to the chitosan degradation over the catalytic materials, for the series supported on alumina, only when the organic modifier was first impregnated on the carrier (ChP3/A) enhanced DBT HDS is observed, which could probably be attributed to better NiMo species dispersion. On the other hand, when the acidic chitosan solution was deposited over the alumina substrate previously impregnated with NiMoP solution (sample ChP4/A), the effect on the HDS was negative. In this regard, the TG-DTA showed that the organic additive over that material evolved in a similar way to neat chitosan, which means weak interaction of the polysaccharide with either the support or the metallic. In the case of aluminatitania-supported materials, apparently the effect of chitosan is negligible, but there is a slight increase of the activity for the sample where the chitosan was impregnated in the last preparation stage (material $\mathrm{ChP} 4 / \mathrm{AT}$ ). That result contrasts with that observed for the corresponding sample with alumina carrier (solid ChP4/A), but for the latter the TG-DTA showed a different high-temperature profile (see Figures 6 and 7). Thermal studies reveal that significant amounts of carbonaceous species remain over those catalyst surfaces, which is more evident in the sample ChP4/AT than over the ChP4/A one. In fact, the C 1s XPS signals (see Figure 9) were in line with the thermal studies and evidenced the presence of augmented amount of carbon species in the ChP4/AT sample, which could be responsible for the enhanced catalytic activity. In this line, Wang et al. [57] recently studied $\mathrm{NiMo} / \mathrm{TiO}_{2}$ catalysts modified by carbon-finding that trace amounts of carbon in HDS catalysts improved sulfide active species dispersion and also suppressed further carbon deposition on catalysts surface. They also reported that $\mathrm{TiO}_{2}$ modified with carbon nanoparticles could weaken the interaction between $\mathrm{TiO}_{2}$ and $\mathrm{H}_{2} \mathrm{~S}$ produced during hydrodesulfurization, resulting in facilitated hydrogen sulfide desorption from the catalyst surface, which leads to higher HDS activity by rapid elimination of that deleterious by-product. 
Our findings in the present study contrast with those published in a previous report [16] in which sulfided catalysts based on chitosan-modified NiMo supported on alumina did not increase the catalytic activity as compared to corresponding conventional materials with $\mathrm{Al}_{2} \mathrm{O}_{3}$ carrier, regardless of the chitosan: $\mathrm{Ni}$ ratio used. It is worth mentioning that in those formulations the acid used to dissolve chitosan was $\mathrm{HNO}_{3}$ and in the present case we used phosphoric one; thus, as mentioned above, phosphorylated chitosan could be formed [35], thereby leading to the formation of nickel complexes, sulfidation of $\mathrm{Ni}^{2+}$ species being delayed, which accounts for improved DBT HDS. In the previous study, highly efficient sites were present in low concentrations; apparently, in those catalysts, the amount of such sites is sufficient for better $\mathrm{Ni}$ integration on the edges of existent $\mathrm{MoS}_{2}$ slabs.

\section{Conclusions}

The present study demonstrated that the order of supported components addition during preparation of chitosanmodified materials influences both their catalytic activity and selectivity to various products. We found that chitosan degradation also depends on that addition order. Also, the aforementioned effect is more pronounced on the aluminathan on the alumina-titania-supported samples, which could be associated with the interaction between surface acid sites on alumina and $\mathrm{OH}$ and $\mathrm{NH}$ groups of chitosan. In both series of materials, when chitosan was impregnated first onto the support, its degradation continuously evolved. However, when the organic additive was deposited impregnated onto the material previously impregnated with NiMo-containing solution, its thermal degradation resembled that of the neat biopolymer. However, over alumina-titania, the hightemperature thermal events were more complex, which led to the formation of higher amount of surface carbon species.

Activity studies (dibenzothiophene hydrodesulfurization) carried out in presence of corresponding sulfided catalysts showed that ChP3/A is 34\% more active, as compared to the ChP2/A reference material, while for ChP4/AT that enhancement is around 23\%, as to the HDS activity over the ChP2/AT solid. The product distribution was also modified, augmented selectivity towards biphenyl from direct desulfurization (DDS) pathway being observed for the chitosanmodified sulfide formulations. That fact is most probably due to more efficient $\mathrm{MoS}_{2}$ phase promotion by nickel in those catalysts prepared with organic additive that could be associated with existence of highly efficient HDS sites, though at lower concentration.

Surface carbonaceous deposits on the ChP4/AT sample could contribute to improving its catalytic properties. The higher surface area of alumina support, as compared to the alumina-titania one, could also play an important role in the better performance of materials with the former carrier, that being due to improved sulfided phases. Finally, augmented HDS activity of some formulations could be ascribed to formation of phosphorylated chitosan-nickel complex, which could delay $\mathrm{Ni}^{2+}$ sulfidation, favoring then mixed NiMoS phases formation on those catalysts' surface.

\section{Conflict of Interests}

The authors declare that there is no conflict of interests regarding the publication of this paper.

\section{Acknowledgments}

Guillermina Ríos-Caloch and Víctor Santes wish to acknowledge the financial support from the Instituto Politécnico Nacional (SIP-20151754) and CONACYTSENER-HIDROCARBUROS (136363).

\section{References}

[1] K. Al-Dalama and A. Stanislaus, "Temperature programmed reduction of $\mathrm{SiO}_{2}-\mathrm{Al}_{2} \mathrm{O}_{3}$ supported $\mathrm{Ni}$, Mo and NiMo catalysts prepared with EDTA," Thermochimica Acta, vol. 520, no. 1-2, pp. 67-74, 2011.

[2] M. A. Lélias, E. Le Guludec, L. Mariey et al., "Effect of EDTA addition on the structure and activity of the active phase of cobalt-molybdenum sulfide hydrotreatment catalysts," Catalysis Today, vol. 150, no. 3-4, pp. 179-185, 2010.

[3] H. Topsøe, B. S. Clausen, and F. E. Massoth, Hydrotreating Catalysis, Springer, Berlin, Germany, 1996.

[4] D. Ferdous, N. N. Bakhshi, A. K. Dalai, and J. Adjaye, "Synthesis, characterization and performance of NiMo catalysts supported on titania modified alumina for the hydroprocessing of different gas oils derived from Athabasca bitumen," Applied Catalysis B: Environmental, vol. 72, no. 1-2, pp. 118-128, 2007.

[5] V. Santes, J. Herbert, M. T. Cortez et al., "Catalytic hydrotreating of heavy gasoil FCC feed on alumina-titania-supported NiMo catalysts," Applied Catalysis A: General, vol. 281, no. 1-2, pp. 121128, 2005.

[6] J. Ramírez, G. Macías, L. Cedeño, A. Gutiérrez-Alejandre, R. Cuevas, and P. Castillo, "The role of titania in supported Mo, CoMo, NiMo, and NiW hydrodesulfurization catalysts: analysis of past and new evidences," Catalysis Today, vol. 98, no. 1-2, pp. 19-30, 2004.

[7] J. R. Grzechowiak, I. Wereszczako-Zielińska, and K. Mrozińska, "HDS and HDN activity of molybdenum and nickelmolybdenum catalysts supported on alumina-titania carriers," Catalysis Today, vol. 119, no. 1-4, pp. 23-30, 2007.

[8] K. Nakano, W. Pang, J.-K. Lee, J.-I. Park, S.-H. Yoon, and I. Mochida, "Activity of alumina-silica-supported NiMoS prepared by controlled mixing of alumina into $\mathrm{SiO}_{2}$ hydrogels for HDS of gas oil," Fuel Processing Technology, vol. 92, no. 5, pp. 1012-1018, 2011.

[9] Usman, T. Yamamoto, T. Kubota, and Y. Okamoto, "Effect of phosphorus addition on the active sites of a $\mathrm{Co}-\mathrm{Mo} / \mathrm{Al}_{2} \mathrm{O}_{3}$ catalyst for the hydrodesulfurization of thiophene," Applied Catalysis A: General, vol. 328, no. 2, pp. 219-225, 2007.

[10] S. A. Giraldo and A. Centeno, "Isomerization and cracking under HDS conditions using $\gamma$-alumina modified with boron as catalysts support," Catalysis Today, vol. 133-135, no. 1-4, pp. 255-260, 2008.

[11] J. J. Lee, H. Kim, J. H. Koh, A. Jo, and S. H. Moon, "Performance of fluorine-added $\mathrm{CoMoS} / \mathrm{Al}_{2} \mathrm{O}_{3}$ prepared by sonochemical and chemical vapor deposition methods in the hydrodesulfurization of dibenzothiophene and 4,6-dimethyldibenzothiophene," Applied Catalysis B: Environmental, vol. 61, no. 3-4, pp. 274280, 2005. 
[12] B. M. Vogelaar, N. Kagami, T. F. van der Zijden, A. D. van Langeveld, S. Eijsbouts, and J. A. Moulijn, "Relation between sulfur coordination of active sites and HDS activity for Mo and NiMo catalysts," Journal of Molecular Catalysis A: Chemical, vol. 309, no. 1-2, pp. 79-88, 2009.

[13] N. Koizumi, Y. Hamabe, S. Yoshida, and M. Yamada, "Simultaneous promotion of hydrogenation and direct desulfurization routes in hydrodesulfurization of 4,6-dimethyldibenzothiophene over $\mathrm{NiW}$ catalyst by use of $\mathrm{SiO}_{2}-\mathrm{Al}_{2} \mathrm{O}_{3}$ support in combination with trans-1,2-diaminocyclohexane- $N, N, N^{\prime}, N^{\prime}$-tetraacetic acid," Applied Catalysis A: General, vol. 383, no. 1-2, pp. 79-88, 2010.

[14] R. Cattaneo, F. Rota, and R. Prins, "An XAFS study of the different influence of chelating ligands on the HDN and HDS of $\gamma-\mathrm{Al}_{2} \mathrm{O}_{3}$-supported NiMo catalysts," Journal of Catalysis, vol. 199, no. 2, pp. 318-327, 2001.

[15] E. Guibal, "Heterogeneous catalysis on chitosan-based materials: a review," Progress in Polymer Science, vol. 30, no. 1, pp. 71109, 2005.

[16] G. Ríos-Caloch, V. Santes, J. Escobar, M. Valle-Orta, M. C. Barrera, and M. Hernández-Barrera, "Effect of chitosan addition on $\mathrm{NiMo} / \mathrm{Al}_{2} \mathrm{O}_{3}$ catalysts for dibenzothiophene hydrodesulfurization," International Journal of Chemical Reactor Engineering, vol. 10, no. 1, pp. 1542-6580, 2012.

[17] D. Valencia and T. Klimova, "Citric acid loading for $\mathrm{MoS}_{2}$-based catalysts supported on SBA-15. New catalytic materials with high hydrogenolysis ability in hydrodesulfurization," Applied Catalysis B: Environmental, vol. 129, pp. 137-145, 2013.

[18] J. Escobar, J. A. Toledo, A. W. Gutiérrez et al., "Enhanced dibenzothiophene desulfurization over NiMo catalysts simultaneously impregnated with saccharose," Studies in Surface Science and Catalysis, vol. 175, pp. 767-770, 2010.

[19] F. Bataille, J.-L. Lemberton, P. Michaud et al., "Alkyldibenzothiophenes hydrodesulfurization-promoter effect, reactivity, and reaction mechanism," Journal of Catalysis, vol. 191, no. 2, pp. 409-422, 2000.

[20] L. Kaluža, D. Gulková, Z. Vít, and M. Zdražil, "Effect of support type on the magnitude of synergism and promotion in CoMo sulphide hydrodesulphurisation catalyst," Applied Catalysis A: General, vol. 324, no. 1-2, pp. 30-35, 2007.

[21] J. Escobar, M. C. Barrera, J. A. Toledo et al., "Effect of ethyleneglycol addition on the properties of P-doped $\mathrm{NiMo} / \mathrm{Al}_{2} \mathrm{O}_{3} \mathrm{HDS}$ catalysts: part I. Materials preparation and characterization," Applied Catalysis B: Environmental, vol. 88, no. 3-4, pp. 564-575, 2009.

[22] J. Zawadzki and H. Kaczmarek, "Thermal treatment of chitosan in various conditions," Carbohydrate Polymers, vol. 80, no. 2, pp. 394-400, 2010.

[23] S.-D. Li, C.-H. Zhang, J.-J. Dong et al., "Effect of cupric ion on thermal degradation of quaternized chitosan," Carbohydrate Polymers, vol. 81, no. 2, pp. 182-187, 2010.

[24] A. T. Paulino, J. I. Simionato, J. C. Garcia, and J. Nozaki, "Characterization of chitosan and chitin produced from silkworm crysalides," Carbohydrate Polymers, vol. 64, no. 1, pp. 98-103, 2006.

[25] C. Demetgül and S. Serin, "Synthesis and characterization of a new vic-dioxime derivative of chitosan and its transition metal complexes," Carbohydrate Polymers, vol. 72, no. 3, pp. 506-512, 2008.

[26] J. Coates, Encyclopedia of Analytical Chemistry, John Wiley \& Sons, 2000.
[27] F. Tian, Y. Liu, K. Hu, and B. Zhao, "Study of the depolymerization behavior of chitosan by hydrogen peroxide," Carbohydrate Polymers, vol. 57, no. 1, pp. 31-37, 2004.

[28] K. R. Krishnapriya and M. Kandaswamy, "A new chitosan biopolymer derivative as metal-complexing agent: synthesis, characterization, and metal(II) ion adsorption studies," Carbohydrate Research, vol. 345, no. 14, pp. 2013-2022, 2010.

[29] H. V. Fajardo and L. F. D. Probst, "Production of hydrogen by steam reforming of ethanol over $\mathrm{Ni} / \mathrm{Al}_{2} \mathrm{O}_{3}$ spherical catalysts," Applied Catalysis A: General, vol. 306, pp. 134-141, 2006.

[30] R. H. P. Devamani and M. Alagar, "Synthesis and characterization of aluminium phosphate nanoparticles," International Journal of Applied Science and Engineering Research, vol. 1, no. 6, pp. 769-775, 2012.

[31] H. Wu, W. Hou, J. Wang, L. Xiao, and Z. Jiang, "Preparation and properties of hybrid direct methanol fuel cell membranes by embedding organophosphorylated titania submicrospheres into a chitosan polymer matrix," Journal of Power Sources, vol. 195, no. 13, pp. 4104-4113, 2010.

[32] W. S. W. Ngah and S. Fatinathan, "Adsorption characterization of $\mathrm{Pb}(\mathrm{II})$ and $\mathrm{Cu}$ (II) ions onto chitosan-tripolyphosphate beads: kinetic, equilibrium and thermodynamic studies," Journal of Environmental Management, vol. 91, no. 4, pp. 958-969, 2010.

[33] T. Roncal-Herrero, J. D. Rodríguez-Blanco, L. G. Benning, and E. H. Oelkers, "Precipitation of iron and aluminum phosphates directly from aqueous solution as a function of temperature from 50 to $200^{\circ}$ C, "Crystal Growth \& Design, vol. 9, no. 12, pp. 5197-5205, 2009.

[34] D. Nicosia and R. Prins, "The effect of phosphate and glycol on the sulfidation mechanism of $\mathrm{CoMo} / \mathrm{Al}_{2} \mathrm{O}_{3}$ hydrotreating catalysts: an in situ QEXAFS study," Journal of Catalysis, vol. 231, no. 2, pp. 259-268, 2005.

[35] R. Jayakumar, H. Nagahama, T. Furuike, and H. Tamura, "Synthesis of phosphorylated chitosan by novel method and its characterization," International Journal of Biological Macromolecules, vol. 42, no. 4, pp. 335-339, 2008.

[36] K. Sunitha, S. V. Satyanarayana, and S. Sridhar, "Phosphorylated chitosan membranes for the separation of ethanol-water mixtures by pervaporation," Carbohydrate Polymers, vol. 87, no. 2, pp. 1569-1574, 2012.

[37] R. Jayakumar, R. L. Reis, and J. F. Mano, "Synthesis and characterization of $N$-methylenephenyl phosphonic chitosan," Journal of Macromolecular Science Part A: Pure and Applied Chemistry, vol. 44, no. 3, pp. 271-275, 2007.

[38] P. Atanasova, R. López Cordero, L. Mintchev, T. Halachev, and A. López Agudo, "Temperature programmed reduction of the oxide form of $\mathrm{PNiMo} / \mathrm{Al}_{2} \mathrm{O}_{3}$ catalysts before and after water extraction," Applied Catalysis A: General, vol. 159, no. 1-2, pp. 269-289, 1997.

[39] L. Balau, G. Lisa, M. I. Popa, V. Tura, and V. Melnig, "Physicochemical properties of chitosan films," Central European Journal of Chemistry, vol. 2, no. 4, pp. 638-647, 2004.

[40] N. C. Braier and R. A. Jishi, "Density functional studies of $\mathrm{Cu}^{2+}$ and $\mathrm{Ni}^{2+}$ binding to chitosan," Journal of Molecular Structure: THEOCHEM, vol. 499, no. 1-3, pp. 51-55, 2000.

[41] Y. Vijaya, S. R. Popuri, V. M. Boddu, and A. Krishnaiah, "Modified chitosan and calcium alginate biopolymer sorbents for removal of nickel (II) through adsorption," Carbohydrate Polymers, vol. 72, no. 2, pp. 261-271, 2008. 
[42] S.-T. Lee, F.-L. Mi, Y.-J. Shen, and S.-S. Shyu, "Equilibrium and kinetic studies of copper(II) ion uptake by chitosantripolyphosphate chelating resin," Polymer, vol. 42, no. 5, pp. 1879-1892, 2001.

[43] F. A. López, A. L. R. Mercê, F. J. Alguacil, and A. López-Delgado, "A kinetic study on the thermal behaviour of chitosan," Journal of Thermal Analysis and Calorimetry, vol. 91, no. 2, pp. 633-639, 2008.

[44] V. Georgieva, D. Zvezdova, and L. Vlaev, "Non-isothermal kinetics of thermal degradation of chitosan," Chemistry Central Journal, vol. 6, no. 1, article 81, 10 pages, 2012.

[45] J. Aburto, M. Moran, A. Galano, and E. Torres-García, "Nonisothermal pyrolysis of pectin: a thermochemical and kinetic approach," Journal of Analytical and Applied Pyrolysis, vol. 112, pp. 94-104, 2015.

[46] E. Morgado Jr., J. L. Zotin, M. A. S. de Abreu, D. D. O. Rosas, P. M. Jardim, and B. A. Marinkovic, "Characterization and hydrotreating performance of NiMo catalysts supported on nanostructured titanate," Applied Catalysis A: General, vol. 357, no. 2, pp. 142-149, 2009.

[47] J. A. R. van Veen, G. Jonkers, and W. H. Hesselink, "Interaction of transition-metal acetylacetonates with $\gamma-\mathrm{Al}_{2} \mathrm{O}_{3}$ surfaces," Journal of the Chemical Society, Faraday Transactions 1: Physical Chemistry in Condensed Phases, vol. 85, no. 2, pp. 389-413, 1989.

[48] G. Ramis, G. Busca, and V. Lorenzelli, "Structural effects on the adsorption of alcohols on titanium dioxides," Journal of the Chemical Society, Faraday Transactions, vol. 1, no. 83, pp. 15911599, 1987.

[49] A. T. Paulino, M. R. Guilherme, A. V. Reis, E. B. Tambourgi, J. Nozaki, and E. C. Muniz, "Capacity of adsorption of $\mathrm{Pb}^{2+}$ and $\mathrm{Ni}^{2+}$ from aqueous solutions by chitosan produced from silkworm chrysalides in different degrees of deacetylation," Journal of Hazardous Materials, vol. 147, no. 1-2, pp. 139-147, 2007.

[50] T. Weber, J. C. Muijsers, J. H. M. C. van Wolput, C. P. J. Verhagen, and J. W. Niemantsverdriet, "Basic reaction steps in the sulfidation of crystalline $\mathrm{MoO}_{3}$ to $\mathrm{MoS}_{2}$, as studied by X-ray photoelectron and infrared emission spectroscopy," The Journal of Physical Chemistry C, vol. 100, no. 33, pp. 14144-14150, 1996.

[51] M. Anwar, C. A. Hogarth, and R. Bulpett, "An XPS study of amorphous $\mathrm{MoO}_{3} / \mathrm{SiO}$ films deposited by co-evaporation," Journal of Materials Science, vol. 25, no. 3, pp. 1784-1788, 1990.

[52] H. Al-Kandari, A. M. Mohamed, F. Al-Kharafi, M. I. Zaki, and A. Katrib, "Modification of the catalytic properties of $\mathrm{MoO}_{2-x}(\mathrm{OH})_{y}$ dispersed on $\mathrm{TiO}_{2}$ by $\mathrm{Pt}$ and Cs additives," Applied Catalysis A: General, vol. 417-418, pp. 298-305, 2012.

[53] R. S. Vieira, M. L. M. Oliveira, E. Guibal, E. RodríguezCastellón, and M. M. Beppu, "Copper, mercury and chromium adsorption on natural and crosslinked chitosan films: an XPS investigation of mechanism," Colloids and Surfaces A: Physicochemical and Engineering Aspects, vol. 374, no. 1-3, pp. 108-114, 2011.

[54] L. Dambies, C. Guimon, S. Yiacoumi, and E. Guibal, "Characterization of metal ion interactions with chitosan by X-ray photoelectron spectroscopy," Colloids and Surfaces A: Physicochemical and Engineering Aspects, vol. 177, no. 2-3, pp. 203-214, 2001.

[55] C. Xiang, Y.-M. Chai, J. Fan, and C.-G. Liu, "Effect of phosphorus on the hydrodesulfurization and hydrodenitrogenation performance of presulfided $\mathrm{NiMo} / \mathrm{Al}_{2} \mathrm{O}_{3}$ catalyst," Journal of Fuel Chemistry and Technology, vol. 39, no. 5, pp. 355-360, 2011.
[56] O. Y. Gutiérrez and T. Klimova, "Effect of the support on the high activity of the $(\mathrm{Ni}) \mathrm{Mo} / \mathrm{ZrO}_{2}$-SBA-15 catalyst in the simultaneous hydrodesulfurization of DBT and 4,6-DMDBT," Journal of Catalysis, vol. 281, no. 1, pp. 50-62, 2011.

[57] H. Wang, X. Cheng, B. Xiao, C. Wang, L. Zhao, and Y. Zhu, "Surface carbon activated $\mathrm{NiMo} / \mathrm{TiO}_{2}$ catalyst towards highly efficient hydrodesulfurization reaction," Catalysis Surveys from Asia, vol. 19, no. 2, pp. 78-87, 2015. 

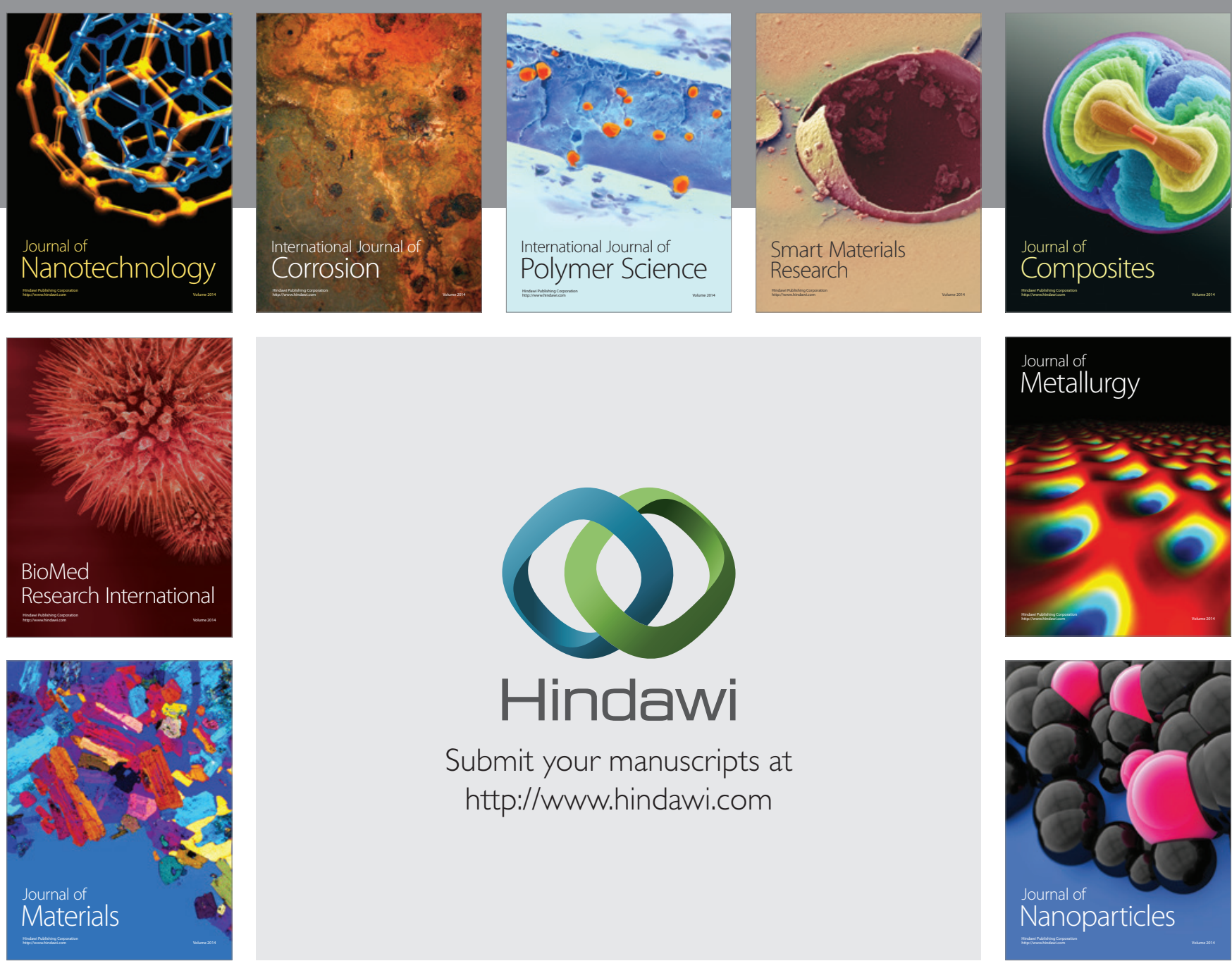

\section{Hindawi}

Submit your manuscripts at

http://www.hindawi.com

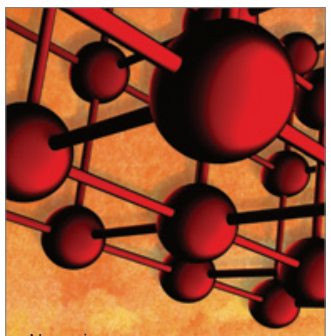

Materials Science and Engineering
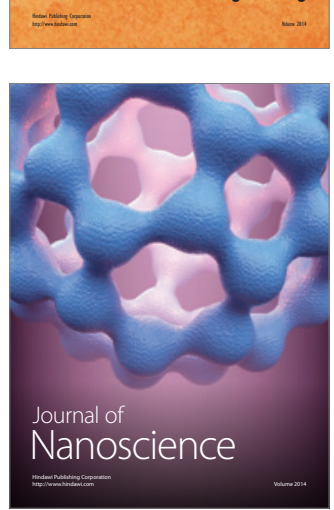
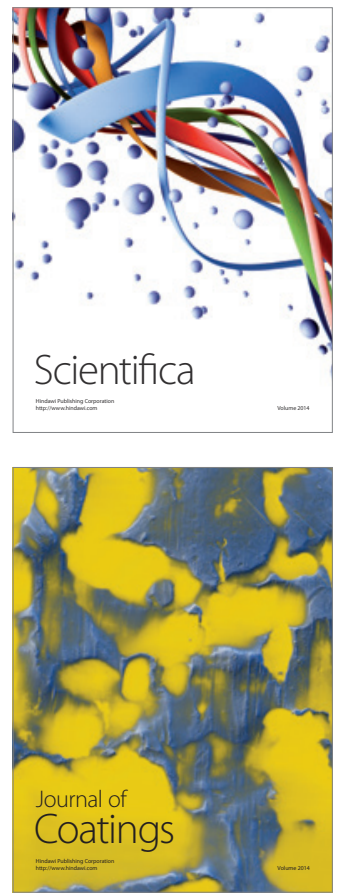
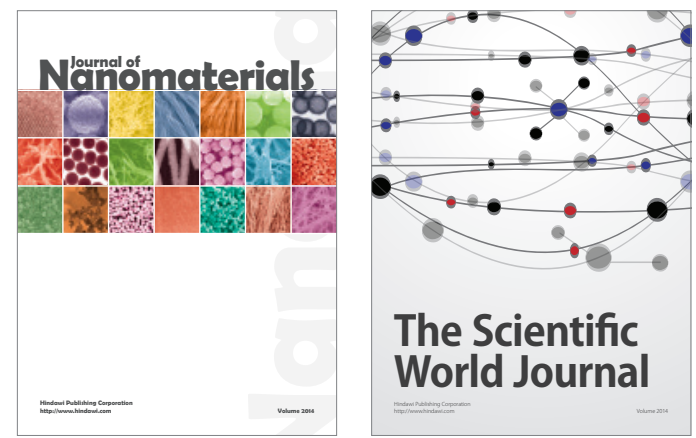

The Scientific World Journal
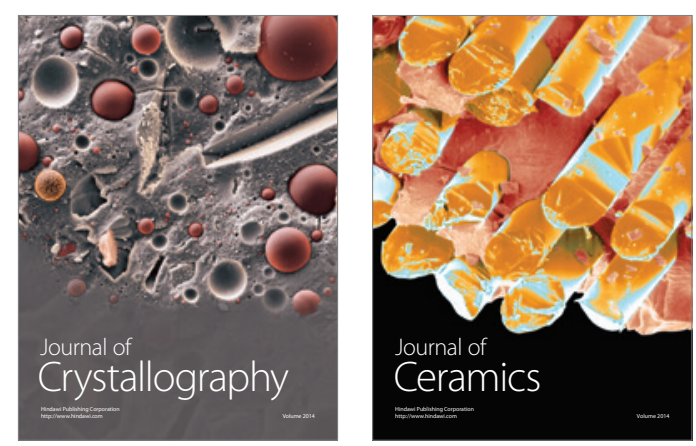
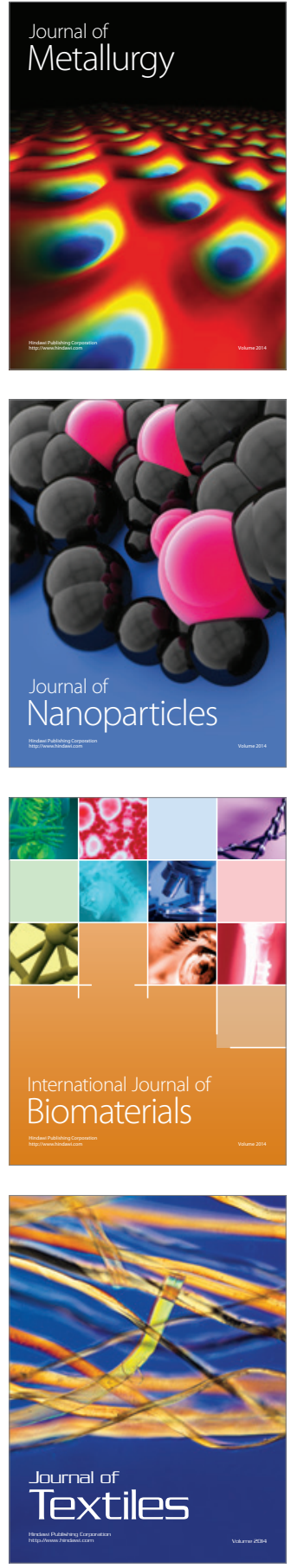